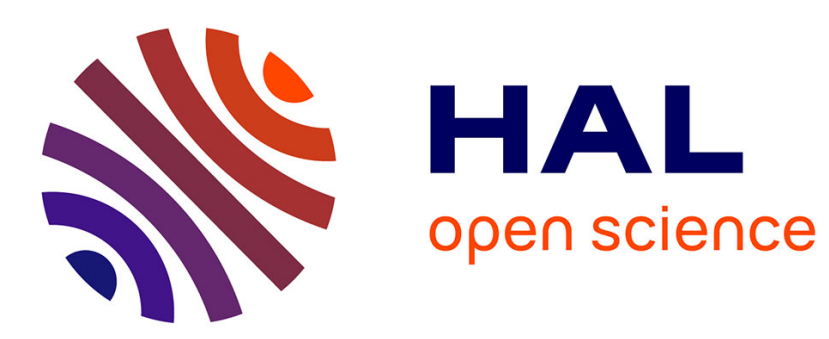

\title{
Predicting Financial Distress in a High-Stress Financial World: The Role of Option Prices as Bank Risk Metrics
}

Jérôme Coffinet, Adrian Pop, Muriel Tiesset

\section{To cite this version:}

Jérôme Coffinet, Adrian Pop, Muriel Tiesset. Predicting Financial Distress in a High-Stress Financial World: The Role of Option Prices as Bank Risk Metrics. 2010. hal-00547744

\author{
HAL Id: hal-00547744 \\ https://hal.science/hal-00547744
}

Preprint submitted on 17 Dec 2010

HAL is a multi-disciplinary open access archive for the deposit and dissemination of scientific research documents, whether they are published or not. The documents may come from teaching and research institutions in France or abroad, or from public or private research centers.
L'archive ouverte pluridisciplinaire HAL, est destinée au dépôt et à la diffusion de documents scientifiques de niveau recherche, publiés ou non, émanant des établissements d'enseignement et de recherche français ou étrangers, des laboratoires publics ou privés. 
EA 4272

\title{
Predicting Financial Distress in a High-Stress Financial World: The Role of Option Prices as Bank Risk Metrics
}

\author{
Jérôme Coffinet $\left(^{*}\right)$ \\ Adrian Pop $\left.{ }^{* *}\right)$ \\ Muriel Tiesset $\left(^{*}\right)$
}

$2010 / 41$

INSTITUT

d'ECONOMIE

et de MANAGEMENT

de NANTES - IAE $\left.{ }^{*}\right)$ Banque de France - Paris - France

$\left(^{* *}\right)$ LEMNA - Université de Nantes - France

Laboratoire d'Economie et de Management Nantes-Atlantique

Université de Nantes

Chemin de la Censive du Tertre - BP 52231

44322 Nantes cedex 3 - France

www.univ-nantes.fr/iemn-iae/recherche

UNIVERSITÉ DE NANTES 


\title{
Predicting Financial Distress in a High-Stress Financial World: The Role of Option Prices as Bank Risk Metrics
}

\author{
Jérôme Coffinet ${ }^{\mathrm{a}}$
}

Adrian Pop ${ }^{\mathrm{b}}$

and

Muriel Tiesset ${ }^{\mathrm{c}}$

First version: December 2009; This version: October 2010

Abstract: The current financial crisis offers a unique opportunity to investigate the leading properties of market indicators in a stressed environment and their usefulness from a banking supervision perspective. One pool of relevant information that has been little explored in the empirical literature is the market for bank's exchange-traded option contracts. In this paper, we first extract implied volatility indicators from the prices of the most actively traded option contracts on financial firms' equity. We then examine empirically their ability to predict financial distress by applying survival analysis techniques to a sample of large US financial firms. We find that market indicators extracted from option prices significantly explain the survival time of troubled financial firms and do a better job in predicting financial distress than other time-varying covariates typically included in bank failure models. Overall, both accounting information and option prices contain useful information of subsequent financial problems and, more importantly, the combination produces good forecasts in a high-stress financial world, full of doubts and uncertainties.

Keywords: Financial distress; Financial system oversight; Market discipline; Options; Implied volatility; Survival analysis

$$
\text { JEL Codes: G21; G28 }
$$

${ }^{a}$ Banque de France, French Prudential Supervisory Authority, Banking Studies Division, 1 Rue de la Vrillière, 75001 Paris, France; Tel.: +33-1-42-92-60-18 ; fax: +33-1-42-92-59-57. Email: jerome.coffinet@acp.banque-france.fr

${ }^{b}$ Institute of Banking \& Finance, University of Nantes (LEMNA), Chemin de la Censive du Tertre BP 52231, 44322 Nantes, Cedex 3, France; Tel.: +33-2-40-14-16-54; fax: +33-2-40-14-16-50. E-mail: adrian.pop@univ-nantes.fr (Corresponding author)

${ }^{\mathrm{c}}$ Banque de France, French Prudential Supervisory Authority, Banking Studies Division, 1 Rue de la Vrillière, 75001 Paris, France; Tel.: +33-1-42-92-66-16; fax: +33-1-42-92-59-57. E-mail: muriel.tiesset@acp.banque-france.fr

Acknowledgements

We are grateful to Gilbert Colletaz, Henri Pagès, Christian Rauch, Catherine RefaitAlexandre, Larry Wall and participants at the $14^{\text {th }}$ Annual European Conference of the Financial Management Association (FMA), 42 ${ }^{\text {th }}$ Annual Conference of the Money, Macro, and Finance (MMF) Research Group, Banque de France Research Foundation Seminar, $58^{\text {th }}$ Annual Meetings of the French Economics Association (AFSE), $27^{\text {th }}$ International Symposium on Banking and Monetary Economics and seminar participants at the Banque de France, University of Nantes (LEMNA) and University of Orleans (LEO) for their useful comments. The views expressed in this article are exclusively those of the authors and do not necessarily represent those of the institutions they belong to, especially the Banque de France or the French Supervisory Prudential Authority. All remaining errors are our own responsibility. 


\section{Executive summary}

Both theoretical and empirical literature convincingly argue that private market participants (shareholders, debtholders, large counterparts in derivative markets...) are able to fairly identify risky institutions when the financial system is in good shape. This result is based on the quality of the Hayekian information disseminating process accompanying the price formation alchemy. At the same time, there is a broad consensus that market signals often become erratic and extremely volatile during times of stress, when investors face severe aggregate shocks and markets may stop functioning because systemic risk is at stake. The global financial crisis that broke out in the Summer 2007 provides a unique opportunity to test directly the validity of such a broad consensus and to investigate the leading properties of market signals in a highly stressed environment, characterized by a significant number of real-life failure episodes in the financial services industry.

In this paper, we pursue this new direction in the empirical literature and focus on a potential source of information that has been overlooked so far in this research area: the market for exchange-traded option contracts on financial firms' equity. Swidler and Wilcox (2002) are the first to suggest adding time-varying measures of implied volatility (IV) extracted from option prices to the menu of market-based risk indicators that regulators and supervisors should regularly monitor. They based their policy recommendation on the idea that IVs have lower root-meansquared-error forecasts of banks' future share price volatility than historical volatilities do and hence improve forecasts based solely on historical volatilities. They also show that IVs are only imperfectly correlated with other market signals, such as bank share prices and sub-debt yield spreads, which is an encouraging result.

In the present paper, we take a more straightforward approach to gauge the usefulness of option market indicators for micro-prudential purposes. Particularly, instead of assessing the ability of IV to forecast actual, future volatilities of share prices, we use option market indicators to improve the accuracy of survival models typically conceived to predict material deteriorations in financial firms' conditions. Moreover, in contrast to previous literature, which relies extensively on broad definitions of default such as rating downgrades, we use a narrower definition of financial distress by focusing on major corporate events - such as dividend cuts and omissions - that are systematically followed by failures, insolvencies, bankruptcies, management turnovers or massive restructuring activities.

To put into perspective the above-mentioned contributions to the literature, we conduct a comprehensive statistical analysis to assess the ability of early-warning indicators derived from option prices to predict occurrences of distress in the financial services industry. For that purpose, we apply alternative empirical specifications to a sample of large US financial firms ( 75 banks and 180 financial services firms) based on survival analysis: non-parametric tests; semi-parametric (Cox proportional hazards) regressions; and parametric (accelerated failure time) models. Our results indicate that market indicators extracted from option prices significantly explain time-tofailure of distressed financial firms and do a better job in predicting financial distress than other time-varying covariates typically included in bank failure models (profitability ratios; financial 
leverage; operating efficiency; fraction of doubtful assets; composite scores based on financial ratios). Overall, both accounting information and option prices contain useful information of subsequent financial problems and, more importantly, the combination produce better forecasts in a high-stress financial world, full of doubts and uncertainties.

The results are relevant to the current debate around the proposals requiring systemically important financial institutions to issue contingent capital notes, i.e. debt certificates or subordinated bonds that would automatically convert to common equity when a predefined idiosyncratic trigger is reached during a systemic crisis. Most of the proponents of contingent capital advocate for a market-based conversion trigger (e.g. equity prices, CDS spreads) on the grounds that the accounting measures are inherently backward-looking and fail to reflect in a timely manner the true financial conditions of a large and complex banking organization. Yet, the empirical literature remains silent on the ability of market-based indicators to flag financial problems during episodes of extreme stress in the financial system. The present study fills this important gap in the literature and suggests adding market indicators extracted from option prices to the menu of vulnerability metrics that regulators should intensively monitor, especially during a large-scale financial turmoil. 


\section{Introduction and motivation}

The intervention of public authorities in modern banking and financial systems is a ubiquitous phenomenon. In most countries, financial firms are viewed as "special" entities and receive a highly-specific treatment from governments, whatever their political color. In contrast to industrial companies, whose governance is commonly assured by the freemarket forces, financial firms are governed by a mix of private and public arrangements. During their normal activity, financial institutions (FIs) face two kinds of constraints: some are imposed by private market participants (market discipline), others are designed and enforced by public authorities (regulatory discipline). In times of financial crisis, more weight is assigned to regulatory discipline on the grounds that the market discipline mechanism does not function properly, i.e. it is unable to deal efficiently with contagious runs and maintain financial stability or to resolve large financial firms' failures in an orderly manner.

A relevant source of complementarities between public and private governance of FIs is the use of market information to improve the regulatory oversight of the financial system. The so-called "indirect channel" of market discipline in banking supposes that supervisors observe bank securities prices in real time and infer reliable signals concerning the default probabilities of issuing financial firms. To illustrate the modus operandi of indirect (i.e. supervisor-triggered) market discipline, the banking authorities may use the market signals embedded in bank securities prices (along with supervisory data and other flows of private information) when allocating scarce supervisory resources, scheduling on-site exams, calibrating off-site surveillance models, setting up risk-adjusted deposit insurance premia or triggering prompt corrective actions (see Berger, 1991; Flannery, 1998; Evanoff and Wall, 2000).

In practice, the idea of using market signals to facilitate the prudential mission of public authorities has recently drawn increasing attention among bank supervisors (see Curry, Elmer and Fissel, 2004; Schmidt, 2004; Burton and Seale, 2005; Furlong and Williams, 2006). The market indicators most often mentioned in supervisory reports are: stock prices; subordinated debt yield spreads; expected default frequencies (EDFs) and distance-to-default (DD) indicators extracted from equity values; market capitalization; asset volatility; credit ratings; and analysts' opinions. ${ }^{1}$

In order to assess the disciplinary potential of private market participants, the empirical literature attempted to determine the extent to which financial market prices accurately reflect issuers' financial conditions. The first generation empirical studies point towards the absence of adequate pricing: bank securities prices poorly reflect the risk profile (see Berger, 1991; Flannery, 1998). The most plausible explanation for this finding is that during the eighties market participants perceived a high probability of governmental bailout that weakened their monitoring incentives (see Flannery and Sorescu, 1996). ${ }^{2}$ Other studies have

\footnotetext{
${ }^{1}$ In the United States, research projects conducted within the Federal Reserve System have focused recently on the potential use of information extracted from credit derivatives, such as Credit Default Swap (CDS) contracts (see e.g. Furlong and Williams, 2006).

${ }^{2}$ Covitz, Hancock and Kwast (2004) propose an alternative explanation, which pertains to a supply-side
} 
refined and extended this empirical result (see notably Berger, Davies and Flannery, 2000; DeYoung, Flannery, Lang and Sorescu, 2001; Evanoff and Wall, 2001, 2002; Jagtiani and Lemieux, 2001; Covitz, Hancock and Kwast, 2004).

Another strand of this literature examines the ability of market participants to predict individual bank or system-wide fragility and the potential use of market data to improve the accuracy of the off-site surveillance models (see Flannery, 1998, and Evanoff and Wall, 2000). Some recent empirical studies (e.g. Gropp, Vesala and Vulpes, 2006; Krainer and Lopez, 2008) provide evidence that both equity-based measures and yield spreads are useful for detecting material changes in the ratings assigned to banks by their supervisors or international agencies. An interesting and intuitive result is that equity market variables perform less well closer to "default," while credit spreads seem to have much value for supervisor only close to "default."

However, until recently no major, systemic, financial crisis hit developed economies like the United States or Europe. Consequently, the young but growing empirical literature on the role of market data in predicting financial distress relies on "soft" definitions of default, such as external agencies / supervisory rating downgrades. The current global financial crisis offers a unique opportunity to investigate the leading properties of market indicators in a highly stressed macro-economic environment, characterized by severe financial distress and real-life failure episodes among financial firms.

One source of relevant information that has been little explored in the extant empirical literature is the market for bank's exchange-traded option contracts. However, the conventional wisdom says that, at least in normal times, the option market is likely to be informationally more efficient than either equity or bond markets. Indeed, as options are highly leveraged contracts, the lower transaction costs are likely to facilitate speculation and improve liquidity, and hence the informational efficiency of the derivative market (see e.g. Swidler and Wilcox, 2002). Moreover, at least for the largest banking organizations, the market for option contracts on bank equity is active, deep, and sufficiently liquid to provide reliable signals to supervisors. The lack of option data for smaller banks should not prevent researchers to assess the usefulness of market-related indicators extracted from option prices that are available only for the largest banks. As the current financial crisis has clearly revealed, the opaqueness and complexity of the largest financial firms' activities and risk profiles pose the greatest challenge to supervisors and banking authorities.

Although less research has focused on the informational content of option prices and their potential use to improve the regulatory oversight of FIs, there is one notable exception. Swidler and Wilcox (2002) provide evidence that the volatility measure implied by the prices of options on the banks' shares co-varies with the market volatility and this covariance is negatively related with the capital ratio (that is, bank capital reduces the response of implied volatilities to market volatility). They also show that implied volatilities (IVs) have lower root-mean-squared-error forecasts of banks' future share price volatility than

effect in the debt market and the endogeneity of the decision to issue bank debt securities. 
historical volatilities do and hence improve forecasts based solely on historical volatilities. Finally, they document that IVs are imperfectly correlated with bank share prices and subdebt yield spreads. This finding suggests that bank supervisors should add IVs to their menu of market-based signals actually in use.

While similar in spirit, our study distinguishes from the previous works in several major respects. First, the empirical studies in this area focused on isolated near-failure events occurring during "benign" or tranquil sample periods. In contrast, the present paper investigates the ability of market indicators to flag distress episodes in a stressful financial world, where a large number of FIs are likely to be at risk of failure. Indeed, the vast majority of failure events included in our sample have occurred toward the end of the analyzed period (2007-2008). The recent financial turmoil provides an interesting natural experiment framework that allows us to test directly the hypothesis according to which the market discipline mechanism does not function properly in times of extreme financial duress and systemic meltdown. ${ }^{3}$ Second, compared to Swidler and Wilcox (2002), we take a more straightforward approach to gauge the usefulness of option market indicators for prudential purposes. Instead of assessing the ability of IV to forecast actual, future volatilities of share prices, we use option market indicators to improve the accuracy (predictive power) of time-to-failure models that are typically conceived to predict failures or material deteriorations in financial firms' conditions. Third, in contrast to previous literature, which relies extensively on "soft" definitions of default (e.g. rating downgrades), we use a narrower definition of financial distress by focusing on major corporate events, namely significant dividend cuts or dividend omissions.

To put into perspective the above-mentioned contributions to the literature, we conduct a comprehensive statistical analysis to assess the ability of early-warning indicators derived from option prices to predict occurrences of distress in the financial services industry. For that purpose, we apply alternative empirical specifications to a sample of large US financial firms (75 banks and 180 financial services firms) based on survival analysis: non-parametric tests; semi-parametric (Cox proportional hazards) regressions; and parametric (accelerated failure time) models. Our findings indicate that market indicators extracted from option prices significantly explain the survival time of distressed financial firms and do a better job in predicting financial distress than other time-varying covariates typically included in bank failure models.

The results are relevant to the current debate around the proposals requiring systemically important financial institutions to issue contingent capital notes, i.e. debt certificates or subordinated bonds that would automatically convert to common equity when a predefined idiosyncratic trigger is reached during a systemic crisis (Flannery, 2005, 2009ab; Hart and Zingales, 2009; Squam Lake Working Group on Financial Regulation, 2009; Wall, 2010).

\footnotetext{
${ }^{3}$ For illustrative purposes, the Turner Review of global banking regulation published by the Financial Services Authority in March 2009 explicitly states: "A reasonable conclusion is that market discipline expressed via market prices cannot be expected to play a major role in constraining bank risk taking [...]" (Financial Services Authority, 2009, pp. 46-47)
} 
Most of the proponents of contingent capital advocate for a market-based conversion trigger (e.g. equity prices, CDS spreads) on the grounds that the accounting measures are inherently backward-looking and fail to reflect in a timely manner the true financial conditions of a large and complex banking organization. ${ }^{4}$ Yet, the empirical literature remains silent on the ability of market-based indicators to flag financial problems during episodes of extreme stress in the financial system. The present study fills this important gap in the literature and suggests adding market indicators extracted from option prices to the menu of vulnerability metrics that regulators should intensively monitor, especially during a large-scale financial turmoil. ${ }^{5}$

The remainder of the paper is structured as follows. Section 2 describes the methodology used to construct the time-varying IV indicator extracted from option prices. Section 3 briefly presents the option dataset used in our analysis and the sample selection criteria. Section 4 presents the empirical methodology employed in our research and the results of survival analyses. Finally, Section 5 concludes.

\section{Extracting IVs from options prices}

The first step in our analysis consists in constructing a time-varying forward-looking measure of risk from the most actively traded option contracts on the largest international FIs' equity. As each financial firm has a whole specter of option contracts with different strike prices and maturities, a natural choice is to compute a standardized measure of IV. In so doing, we use a methodology that is similar to Swidler and Wilcox (2002). Specifically, our IV estimates are based on the nearest two "at-the-money" options (i.e. the most liquid series) - one above and one below the underlying price - using values from the nearest expiry month options. As it is well known, options are rarely at the money because strike prices are set at standard intervals for each class. Consequently, we interpolate between the two IVs to calculate an estimate of the IV for a hypothetically "at-the-money" Call/Put option. We next average the IVs of the two (Call and Put) option contracts to obtain the IV for options with the strike price nearest to the underlying stock price. The last stage includes an interpolation of maturities in order to obtain IV estimates for a hypothetical at-the-money option having a 30 day constant maturity.

This methodology mirrors the volatility indices calculation commonly used in the market place. Many volatility indices (e.g. the VIX disseminated by Chicago Board Options Exchange) take into account a number of eight options, including a Call and a Put at the two strike prices closest to the money and the nearest two expirations. Hence, our IV measure is

\footnotetext{
${ }^{4}$ For instance, see Flannery (2009a) who notes: "contingent capital driven by a book-valued trigger is virtually worthless."

${ }^{5}$ In the present paper, we do not advocate in favor of an automatic conversion mechanism of contingent capital notes based solely on market indicators derived from option prices. Rather, in order to reduce the incidence of pricing errors in various bank securities markets, one could construct an idiosyncratic "composite" trigger based on equity prices, sub-debt/CDS spreads, and implied volatilities embedded in option prices. This idea is left for future work.
} 
slightly lower because its calculation is based on the "at the money" IV interpolated between only two options (one strike above and one bellow the underlying price). Individual data for each option contract are collected from Bloomberg (see infra, Section 3), which offers options prices directly from exchanges and IVs and other options sensitivities calculations using a proprietary software. The individual IVs reported by Bloomberg are computed using the Cox-Ross-Rubinstein binomial tree model to take into account dividends and the possibility of early exercise.

\section{Data and sample selection}

\subsection{Option market data}

We began by identifying from Bloomberg all banking and financial firms headquartered in the US for which equity Call and Put options are available and actively traded. We are able to find 132 banks and 233 financial firms that have exchange-traded options. For each of the entities included in our sample, we then extract detailed information on their shares' options and the corresponding stock indices options contracts. The implied volatility measures for each option contract (Call/Put, various strike prices and maturities) are also taken from Bloomberg. The "standardized" IV estimates for each financial firm, each business day of the analyzed period, are computed using the methodology described in the previous section. Because not all option contracts began publicly trading at the same time or traded on each day of the entire period, our sample is unbalanced. The maximum time frame for which we are able to construct our standardized IV estimates is February 28, 1995 - December 1, 2008. For some financial firms, the sample period for which we have option prices is however much narrower. To be included in the final sample, the selected entities had to have a minimum time frame of three years of available market information. This criterion further reduces our sample to 255 FIs ( 75 banks and 180 financial services firms).

Descriptive statistics for our main explanatory variable, the Implied Volatility (IV) indicator, are presented in Table 1 (distribution by year). The level of IV was relatively low (27-30\% on average) at the beginning of the considered period (1995-1996), but has increased during periods of stress in the option market (at about $67 \%$ on average in 2008). Table 1 also shows that the variability of the IV indicator follows similar patterns. The standard deviation of IV is much higher during recessions and tumultuous periods for the financial services industry. The maximum values of IV, recorded since the inception of the subprime crisis (i.e. higher than 450\%), are about four times higher than those reached at the beginning of the analyzed period (1995-1997).

\section{$\{$ Table 1$\}$}

\subsection{Financial distress}

As we are interested in the ability of IV to predict financial fragility, our final sample is restricted to include those financial firms that are actively traded in the equity market 
and for which detailed information on the corresponding Call and Put options are available. Generally, these are the largest financial firms in the US. ${ }^{6}$ As a consequence, cases of formal bankruptcies amongst these large financial firms have been extremely rare, even if one takes into account the distress events that have occurred toward the end of the analyzed period (2007-2008). Hence, instead of using outright default as the event variable in our study, we consider an alternative proxy for financial distress. The idea would be that if our option market indicators are able to predict such material weakening in firms' financial condition, which typically precedes formal bankruptcies or reorganizations, supervisors could take action sooner in order to correct the problems, force earlier recapitalization or resolve more efficiently troubled institutions.

Our preferred proxy for financial distress is based on public announcements of dividend cuts and suspensions. To justify our choice, it is worth noting that the financial literature on dividend payout in the financial services industry confirms that dividend reductions convey private information to stakeholders and are an efficient way of unveiling part of the bank assets opacity (see Slovin, Sushka, and Poloncheck, 1999; Bessler and Nohel, 1996, 2000). In general, managers of firms operating in the financial services industry exhibit a very strong reluctance to suspend dividend payouts and avoid cutting dividends unless they face serious financial problems and have no viable alternative. ${ }^{7}$ Consequently, the release of dividend cuts and suspensions constitutes a major and exceptional corporate event per se and provides, in our view, a strong and reliable signal about the financial conditions of a troubled FI. ${ }^{8}$ To reinforce our argument, in the vast majority of dividend reduction cases included in our sample, we observe systematically subsequent regulatory actions, capital restructuring, management turnovers or even formal bankruptcies. Conversely, all of the occurrences of "severe" financial distress (liquidation, bankruptcy, insolvency...) affecting the FIs included in our sample are preceded, without exceptions, by press releases announcing dividend cuts and omissions. Consequently, we are confident that public releases of dividend suspensions

\footnotetext{
${ }^{6}$ Note that most of the off-site surveillance literature is based on samples that are almost always dominated by small banks (see Reidhill and O'Keefe, 1997; Gilbert, Meyer, and Vaughan, 1999, and references therein). The condition of small banks is interesting, but one of the most important lessons from the experience of the recent financial crisis is that there are the largest financial institutions that matter more for financial stability.

${ }^{7}$ This is especially the case when the firm has a long history of paying a reasonable stable dividend rate. In our sample of large financial firms, dividend payments have been very common during the second part of the nineties.

${ }^{8}$ Note that government regulation may interfere with the bank dividend policy by persuading (or forcing) bank managers to cut dividends in order to improve solvability. For instance, in the US, the Prompt Corrective Action (PCA) framework under the Federal Deposit Insurance Corporation Improvement Act (FDICIA) adopted in 1991 requires the suspension of dividend as a mandatory provision if the bank is found to be "undercapitalized." Private discussions with US supervisors confirmed that for most (if not all) banking organizations the decision to cut dividends is made by the regulator and not by the bank's board. Consequently, our empirical model may be viewed as one where the market is predicting when supervisors think the bank's financial conditions have deteriorated sufficiently to require a dividend cut. Our inclusion of "non-bank" financial firms helps to address this concern. Moreover, we are not aware of any observable idiosyncratic measure of bank distress that does not depend in some important way on supervisory judgment.
} 
and significant dividend cuts are an interesting proxy for financial distress.

We collect detailed information regarding dividend payouts (announcement date; exdate; pay date; amount of the announced and previous dividend) by all the financial firms included in our final sample over the period from the beginning of 1995 through the end of 2008 from Bloomberg database. Then, we use Dow Jones Factiva to identify among all dividend payouts the announcements of dividend cuts and omissions that were released to the financial media: Dow Jones and Reuters newswires; key newspapers such as The Wall Street Journal, The New York Times, Washington Post; and other sources available in Factiva. The announcement date is defined as the date of the first published report of the dividend decrease. Table 2 describes the distribution of the event variable by year and by subsector ("banks" vs. "financial services firms"). As expected, the announcements of dividend cuts and omissions occurred during recessions and periods of stress in the financial services industry.

\section{$\{$ Table 2$\}$}

\subsection{Financial ratios and composite scores}

To examine whether option market indicators not only explain the time-to-failure but also improve the accuracy of traditional models based on financial ratios or contain useful information not already incorporated in financial reports, we also collect balance-sheet data from Bloomberg. Accounting information for US financial firms is available on a quarterly basis but do not cover the entire analyzed period for all the FI included in our sample. Following the previous literature (see e.g. Flannery and Sorescu, 1996; Reidhill and O'Keefe, 1997; Gilbert et al., 1999; Gropp et al., 2006), we computed several selected financial ratios that are typically used in traditional off-site surveillance models and mimic the main dimensions of the supervisory rating: profitability, asset portfolio quality, financial leverage, operating efficiency, and the extent to which the financing mix is based on short-term borrowings. We use the financial ratios in our empirical models either as covariates or as a composite rating. The composite rating is computed as in Gropp et al. (2006):

- First, we compute the following financial ratios for each FI at the end of each quarter from 1994 through 2008: ( $i$ ) return on assets (\%); (ii) non-performing assets to total assets (\%); (iii) total debt to common equity (\%); (iv) operating efficiency ratio (\%); and $(v)$ short-term borrowing to total liabilities and equity $(\%)$;

- Second, we inferre the percentile ranking of each FI in each quarter distribution of the five financial ratios;

- Third, we forme four groups with respect to the quartiles of each distribution;

- Four, we assign a score varying from 0 (the best class) to 3 (the worst class) to each FI according to its position in the four groups of each financial ratio; 
- Five, we aggregate the individual scores for each financial ratio into a composite rating.

As the financial ratios, the composite rating is available on a quarterly basis and is sometimes missing for some FIs, particularly at the beginning of our sample period. Descriptive statistics for the main explanatory variables are presented in Table 3.

\section{$\{$ Tables 3\}}

\section{The usefulness of IVs from a micro-prudential perspective}

\subsection{Empirical specifications}

In order to assess the ability of market-based indicators to flag troubled FI and the potential use of our risk metrics for supervisory purposes, we employ survival analysis techniques that despite their relevance are rarely used in the literature on early-warning indicators in banking (see e.g. Cole and Gunther, 1995). To our knowledge, the only exception in the recent literature is Gropp et al. (2006); however, they only use Cox proportional hazard models, which may be unsuitable when the log hazard ratio function is not constant over time.

Survival analysis formalizes the time-to-failure variable as a probability density function of time $f(t)$ or, in its more convenient form, as a survivor function $S(t)=P(T>t)$, describing the probability of surviving beyond time $t$. The probability that the failure event occurs in a given interval $[t ; t+d t)$, conditional upon the FI having survived to time $t$, is expressed as:

$$
P[t \leq T<t+d t \mid T>t]
$$

This probability divided by the width of the interval gives the instantaneous rate of failure or hazard function, i.e. the average (limiting) probability of surviving per unit time period over the interval $[t ; t+d t)$ :

$$
h(t)=\lim _{d t \rightarrow 0} \frac{P[t \leq T<t+d t \mid T>t]}{d t}=\frac{f(t)}{S(t)}
$$

Our empirical approach rests on two different specifications. The first one is based on a Cox proportional hazard $(\mathrm{PH})$ or multiplicative model of the form:

$$
h\left(t \mid I V, X_{1}, X_{2}, \ldots, X_{n}\right)=h_{0}(t) \cdot g\left(I V, X_{1}, X_{2}, \ldots, X_{n}\right)
$$

where $h(\cdot)$ represents the proportional hazard function, $I V$ the IV measure of bank risk, $X_{1}, X_{2}, \ldots, X_{n}$ a set of control variables, $h_{0}(t)$ the baseline hazard, and $g(\cdot)$ a nonnegative function of the covariates. The choice commonly adopted in the survival analysis literature is to let $g(\cdot)$ equal the relative risk, $g\left(I V, X_{1}, X_{2}, \ldots, X_{n}\right)=e^{\beta_{0} I V+\beta_{1} X_{1}+\beta_{2} X_{2}+\ldots+\beta_{n} X_{n}}$. The survival model allows for censoring in the sense that not all FIs included in our final sample experienced a "failure" during the analyzed period (see Kalbfleisch and Prentice, 1980, for more details on the estimation of survival models). 
A crucial assumption behind the Cox proportional hazards specification is that the hazard ratio is proportionally distributed over time. To evaluate this assumption, we perform a test of nonzero slope in a generalized linear regression of the scaled Schoenfeld residuals on various functions of time (see Grambsch and Therneau, 1994). The test is equivalent to evaluate the hypothesis that the log hazard ratio function is constant over time. Although the null hypothesis of zero slope in the appropriate regressions is accepted for some individual discrete covariates, the global test indicate in many cases deviations from the proportional hazards assumption.

To tackle this econometric issue, Gropp et al. (2006) replace in their models the continuous market indicator (i.e. the time-varying covariate) by a dummy variable taking the value of 1 if the indicator is higher than the third quartile of its distribution and 0 otherwise. In this manner, their PH model is no longer rejected because of the violation of the proportional hazard assumption. However, besides the arbitrariness behind the cut-off value chosen in the definition of the dummy variable, some relevant information is likely to be lost when the continuous market indicator is converted to a dummy variable. Consequently, in the present paper we use a second specification based on an alternative modeling choice: the accelerated failure-time (AFT) model.

The AFT specification supposes a linear relationship between the logarithm of the survival time $\ln \left(t_{j}\right)$ and the covariates $\mathbf{X}_{j}$

$$
\ln \left(t_{j}\right)=\mathbf{X}_{j} \boldsymbol{\beta}+\epsilon_{j}
$$

where $\epsilon_{j}$ is the error with density $\varphi(\cdot)$. The assumption on the distributional form of the error term determines the class of the regression models. Particularly, assuming a normal, logistic, extreme-value or three-parameter gamma distribution for the error term, the corresponding regression models are lognormal, log-logistic, Weibull and generalized gamma, respectively. In the present paper, we opt for the log-logistic model, commonly used in the banking literature (see e.g. Cole and Gunther, 1995). To justify our choice and discriminate between various AFT models, we compute for each estimated AFT model the log likelihood and the Akaike Information Criterion (AIC). According to our comparisons, the log-logistic model appears to be the best-fitting model (i.e. exhibiting the largest log likelihood) and the one with the smallest AIC value.

\subsection{Empirical results}

Preliminary evidence: non-parametric tests. Before presenting in greater detail the results of our (semi-)parametric analysis, we aim at drawing some preliminary inferences about the way different covariates affect the patterns of the estimated survivor and cumulative hazard functions. The idea behind the nonparametric approach adopted in this section is to let the data talk for itself without making any assumption about the probability distribution of time to failure. The effects of covariates of interest (i.e. the IV indicator and composite rating), although not modeled explicitly, are analyzed at a basic qualitative 
level, in a graphical and descriptive statistical manner.

Figures 1 depicts the Nelson-Aalen curve estimated for the overall sample, suggesting a step increase of the estimated cumulative hazard function after the Summer 2007 (analysis time $>4,500$ days). Figures $2 \mathrm{a}$ and $2 \mathrm{~b}$ allow to draw preliminary statistical inferences about the impact of the IV indicator and composite score on the survivor functions $S(t)$, i.e. the probability of failing after time $t$ or alternatively the probability of survival past time $t$. Both figures depict Kaplan-Meier estimates of the survivor function across key values of the covariates (low IV value vs. high IV value and low score vs. high score respectively). The IV (score) value is "high" if IV (score) takes larger values than the top 10th percentile of the distribution of IV (score) in the overall sample. ${ }^{9}$ Note that a high IV (score) value characterizes FIs in bad financial conditions. As expected, FIs perceived by the market as being in bad shape have a worse survival experience than the "control" group, i.e. FIs for which the IV indicator takes lower values (see figure 2a). The same difference in survival patterns holds when we plot the survivor function with respect to key values of the composite score (see figure $2 \mathrm{~b}$ ). However, the difference is less pronounced in this case.

\{Figures $1,2 \mathrm{a} \& 2 \mathrm{~b}\}$

We also conduct formal tests of hypothesis for the equality of survivor functions across the two subgroups defined with respect to the IV value. The tests, based on the work of Peto and Peto (1972) and Prentice (1978), use as weight function an estimate of the overall survivor function similar to the Kaplan-Meier estimator and are not susceptible to differences in censoring patterns across groups. Compared with other tests for equality of survivor functions (such as the log-rank test or Wilcoxon test), the Peto-Peto-Prentice test is designed for the special cases when the hazard functions are supposed to vary in ways other than proportionally. Since we suspect that the survival experiences of "banks" and "financial services firms" may differ, we perform a "stratified" test. Precisely, we perform the tests separately for each stratum ("banks" vs. "financial services firms") and then combine the results into one overall statistic ("overall sample"). As revealed by the data reported in Table 4, both "banks" and "financial services firms" exhibit significantly different survival experience across the two subgroups defined with respect to the IV value (low vs. high). In addition, the overall chi squared statistic also rejects the hypothesis for equality of survivor function and suggests that the IV indicator is a significant explanatory factor of the time to failure.

\section{$\{$ Table 4\}}

Semi-parametric survival models. To refine our preliminary findings, Table 5 presents the estimation results from Cox Proportional Hazards regressions using various

\footnotetext{
${ }^{9}$ In alternative specifications we also used the median and $75^{\text {th }}$ percentile of the distribution of IV (score) in the overall sample to define the two subgroups (low IV/score vs. high IV/score). The survivor patterns are quite comparable to those depicted in figures $2 \mathrm{a} \& 2 \mathrm{~b}$.
} 
sets of basic time-varying covariates based on the IV indicator. In order to relax the assumption that banks and other non-bank financial services firms face the same hazard of failure over time, the $\mathrm{PH}$ models are estimated on various subsamples and on the global sample including a bank dummy variable (in the last case, we assume implicitly that the hazard functions for banks and financial services firms have the same shape). To obtain a single, more efficient estimate of the impact of the IV indicator on the survival time, we also perform a stratified analysis. Since we suspect that there is possible dependence among FIs' failure times within various subgroups, the variance-covariance matrix of the coefficients is corrected for clustering using the method described in Lin and Wei (1989). To ease the interpretation of results, we report estimated coefficients in Table 5, not hazard ratios, as well as $p$-values in parenthesis, below each coefficient estimate.

\section{$\{$ Table 5\}}

Whatever the estimated specification, we obtain reasonably similar results. The hazard ratio is increasing in the value of the IV indicator, which is consistent with the nonparametric tests described in the previous section. For illustration purposes, a $10 \%$ increase in the continuous IV indicator increases the hazard by $17-20 \%$ (i.e. $\exp (.016 \times 10)$ ). The coefficient of the bank dummy variable suggests that commercial banks face almost twice of the hazard of non-bank financial services firms (i.e. $\exp (.662)$ ). We also report in Table 6 the results for tests of the proportional-hazard assumption based on analysis of residuals. Globally, the null hypothesis of zero slope is strongly rejected when the IV continuous variable is used in the Cox regressions. ${ }^{10}$ To tackle this econometric issue, we take two distinct approaches. First, following Gropp et al. (2006) we replace in our various models the continuous IV indicator (i.e. the time-varying covariate) by a dummy variable taking the value of 1 if IV value is higher than the $90^{\text {th }}$ percentile of its distribution and 0 otherwise. ${ }^{11}$ Inspecting Table 5 , the $\mathrm{PH}$ specification is no longer rejected because of the violation of the proportional hazard assumption and the IV dummy covariate is positive and significant at the $1 \%$ level. That is, financial firms exhibiting high IV values are much more likely to cut and/or omit dividends and face subsequent financial problems.

However, as already noted, besides the arbitrariness behind the trigger chosen in the definition of the IV dummy variable, some relevant information is likely to be lost when the continuous IV indicator is converted to a dummy. Consequently, we also use a second empirical approach that relies on an alternative modeling choice: the accelerated failure-time (AFT) estimations. The results of the AFT models will be discussed at length in the next section.

\footnotetext{
${ }^{10}$ The Grambsch and Therneau (1994) tests of the proportional-hazards assumption assume homogeneity of variance across subgroups. This assumption may not hold in the special case of the stratified Cox regression. That's why the proportional-hazards assumption is checked in this case separately for each stratum.

${ }^{11}$ Alternatively, we also used the median and $75^{\text {th }}$ percentile of the distribution of IV to define the IV dummy variable. The results are basically the same, both in terms of statistical significance and economic magnitude: the coefficient estimates of the IV dummy defined with respect to the median and top $25^{\text {th }}$ quartile values are $2.40^{* * *}(p$-value $<.000)$ and $2.80^{* * *}(p$-value $<.000)$ respectively (output omitted).
} 
To examine whether market indicators extracted from option prices do a better job in predicting financial distress than other time-varying covariates typically included in bank failure models, we rerun the Cox $\mathrm{PH}$ models including the composite rating based on financial ratios. ${ }^{12}$ The results reported in Table 6 confirm that the composite rating has significant explanatory power in explaining time to failure. The coefficient of the composite score is always positive and significant at the conventional levels (at least 5\%), indicating that financial firms in bad financial conditions (i.e. exhibiting a high score) are more likely to face financial distress.

\section{$\{$ Table 6\}}

However, when we add the option market indicators to the composite rating, the coefficient estimates of the composite score decrease systematically in economic magnitude and pale in significance. Moreover, the goodness of fit of the Cox PH models including both covariates (IV and score) improves significantly relative to models including composite score alone, as revealed by simple comparisons of the associated Wald statistics. ${ }^{13}$ This suggests that the two predictors of financial distress are somewhat complementary to each other and the option market indicator add some information to that already incorporated in FIs' balance-sheets. As before, the proportional hazards assumption is strongly rejected most probably because the existence of strong non-linearities in the relationship between the IV continuous variable and time-to-failure.

Results from the parametric (log-logistic) regressions. An efficient way to exploit the relevant information embedded in the continuous nature of the IV and financial ratios variables is to estimate accelerated failure-time (AFT) models. Fitting parametric survival models allows us to avoid obvious difficulties in properly interpreting the results obtained from miss-specified Cox PH regressions when the proportional hazard assumption is unambiguously rejected. The results of the AFT models estimated on various samples and including different combinations of covariates are reported in Table 7. To ease the comparisons, it is worth noting that, for computational reasons, the results presented in Table 7 are expressed in the accelerated failure-time (AFT) metric. This is very important because negative coefficient estimates translate into a positive impact on the hazard of "failure", whereas a positive coefficient estimate implies that a change in the covariate decreases the hazard.

\section{$\{$ Table 7$\}$}

\footnotetext{
${ }^{12}$ In alternative specifications, we also included the financial ratios variables on an individual basis, but the Cox proportional hazard assumption was systematically rejected according to the results of the zero slope tests. Hence, to save space we decided not to report these additional results.

${ }^{13}$ The piecewise correlation coefficients between quarterly averages of daily IV data and quarter-end composite score indicate a positive but imperfect correlation: $+0.143^{* * *}(p$-value $<.000)$ in the overall sample; $+0.317^{* * *}(p$-value $<.000)$ in the "banks" subsample; and $+0.192^{* * *}(p$-value $<.000)$ in the "financial services firms" subsample. As pointed out by Bliss (2001), statistical theory indicates that combining various signals that are not perfectly correlated produce a more accurate assessment than either one alone.
} 
We begin by estimating simple parametric models and including progressively in the regressions each of the relevant covariates and then combinations of IV, composite rating, and various financial ratios. The continuous and dummy IV variables, as well as the composite score and some financial variables, have significant explanatory power. It is worth noting that the parametric approach allows us to assess the predictive ability of the selected financial ratios on an individual basis. Looking at the financial ratios individually, the most powerful predictors of financial distress are the ratio of non-performing assets to total assets and the financial leverage. To ascertain whether IV indicators do a better job in predicting financial distress than accounting ratios, we compute Wald test statistics for the null hypothesis that $(i)$ all covariates coefficients equal zero; $(i i)$ all financial ratios coefficients equal zero; and (iii) IV coefficient is equal to zero. Simple comparisons of various Wald statistics reported at the bottom of Table 7 confirm that the IV indicator, composite rating, as well as financial ratios taken jointly have significant predictive power in explaining time to failure. However, the most significant contribution to the goodness of fit measure of each "hybrid" model, including both IV and accounting ratios, is due to the IV indicator.

Explaining survival probabilities in a high-stress financial world. To test the ability of the IV indicator to explain the conditional survival probabilities in a high-stress financial world, we rerun all the previous empirical models, semi-parametric as well as parametric, by focusing on the end of the analyzed period. The sampling period for this robustness analysis starts in January 2006 to guarantee that we have at least some past observations for the financial firms that announced dividend cuts and/or omissions in the first half of 2007. The results of the $\mathrm{CPH}$ and AFT models estimated on the sub-sample 2006-2008 and including various combinations of covariates are reported in Table 8a (semiparametric regressions) and Table $8 \mathrm{~b}$ (parametric regressions).

\section{$\{$ Tables 8a\&8b\}}

As it is well known, Cox PH regressions operate only on dates when "failures" actually occur and are in fact a series of conditional logistic regressions, one taking place at each failure time. Since the vast majority of "failure" events (about 80\%) are concentrated during the tumultuous period 2006-2008, we expect little differences between the results obtained by running $\mathrm{CPH}$ regressions on the overall sample and on the stress period. Indeed, the results reported in Table 8a are comparable and fully consistent with the previous findings depicted in Tables $5 \& 6$. Note that we only report in Table 8a those models for which the $\mathrm{PH}$ assumption holds, i.e. the proportional-hazards test statistic based on Schoenfeld residuals is not significant at the $5 \%$ level.

Compared with Cox PH regressions, AFT models are substantially different in the way they exploit the information contained in the data-generating process to obtain coefficient estimates. Particularly, in contrast to Cox PH model, where the choice of time origin plays no significant role, in parametric models the definition of the precise moment when the 
clock starts ticking is crucial. ${ }^{14}$ Consequently, our robustness analysis is more relevant in the particular case of parametric models. The results reported in Table $8 \mathrm{~b}$ confirm that the continuous and dummy IV variables, as well as the composite score, have significant explanatory power and are powerful predictors of financial distress. However, the coefficients of the financial ratios taken individually lose significance (see models $4 \& 5$, Table $8 \mathrm{~b}$ ).

In-sample predictive accuracy, covariate-adjusted survivor functions, and miss-classification errors. An interesting extension to the results reported in previous sections is to investigate the in-sample classification accuracy of the various survival models over the high-stress episode located towards the end of our sample period. For this purpose, we begin by computing the covariate-adjusted survivor functions based on three distinct Cox PH models estimated over the 2006-2008 period (see also Table 8a): ${ }^{15}$ (i) a model including only the IV market-based indicator as explanatory variable; $(i i)$ an alternative model including the composite score as the main independent variable; and (iii) an integrating model including both the IV indicator and composite score. The estimated hazard ratios in all models are significant at the $5 \%$ level. Conditional on the estimates of the hazard ratios from the Cox models, we are able to compute a covariate-adjusted Kaplan-Meier estimate of the "survivor" function, i.e. a probability of survival past time t given survival to time t0, given a value for covariate for each observation and the estimated model parameters (hazard ratios). ${ }^{16}$

\section{\{Figure 3\}}

Figure 3 displays in a convenient manner the estimated conditional survivor functions for two sub-groups: (1) FIs having high IV indicators / composite scores; (2) FIs exhibiting low IV indicators / composite scores. The log rank tests for the equality of survivor functions across the two sub-groups of firms indicate significance at the $1 \%$ level in all three cases.

Following Gropp et al. (2006), we also report in Table 9 the proportion of FIs that did not cut dividends for a certain period of time and having certain characteristics. Precisely, if we consider the model including the IV indicator as the main explanatory variable, we may infer that after one year, 94\% (42\%) of FIs with low (high) IVs did not face a distress event. If we define type I and II classification errors in a standard way, i.e. as "missed failures" and "miss-classified survivals" respectively, it follows that $6 \%$ of FIs were classified as good even though they experienced a failure event (type I error) and $42 \%$ were classified as being in bad shape even though they did not experience a distress event (type II error). The discriminatory power of the model based on the IV indicator only is of $52 \%$ after one year and increases over time. Note that, compared to the IV model, the Cox model including

\footnotetext{
${ }^{14}$ This is because in parametric models the origin of the analysis time determines when the risk of failure begins accumulating.

${ }^{15}$ Because of computational constraints, we report the in-sample predictive accuracy of the Cox PH models only.

${ }^{16}$ In our case, the probability of "survival" refers to the event that a financial institution is not experiencing a dividend cut or suspension.
} 
the composite score generates a much higher number of type II errors (63\% vs. $42 \%)$ and a slightly higher number of occurrences of "missed failures" (9\% vs. 6\%). As a consequence, the model including both the IV indicator and composite score exhibits a somewhat lower discriminatory power than the model based on the IV indicator alone. This result is robust to the cut-off value used in the definition of the two sub-groups of FIs (high vs. low IV / composite score).

\section{$\{$ Table 9\}}

\section{Conclusion}

Both theoretical and empirical literature convincingly argue that private market participants (shareholders, debtholders, large counterparts in derivative markets...) are able to fairly identify risky institutions when the financial system is in good shape. This result is based on the quality of the Hayekian information disseminating process accompanying the price formation alchemy. At the same time, there is a broad consensus that market signals often become erratic and extremely volatile during times of stress, when investors face severe aggregate shocks and markets may stop functioning because systemic risk is at stake. The global financial crisis that broke out in the Summer 2007 provides a unique opportunity to test directly the validity of such a broad consensus and to investigate the leading properties of market signals in a highly stressed environment, characterized by a significant number of failure episodes in the financial services industry.

In this paper, we pursue this new direction in the empirical literature and focus on a potential source of information that has been overlooked so far in this research area: the market for exchange-traded option contracts on financial firms' equity. Particularly, we use option market indicators to improve the accuracy of survival models conceived to predict material deteriorations in financial firms' conditions. Our results indicate that market indicators extracted from option prices significantly explain time-to-failure of distressed financial firms and perform at least as well in predicting financial distress as other time-varying covariates typically included in bank failure models. Overall, both accounting information and option prices contain useful information of subsequent financial problems and, more importantly, the combination produces reasonably good forecasts in a high-stress financial world, full of doubts and uncertainties. 


\section{References}

Berger, A., 1991. Market discipline in banking. Proceedings of a Conference on Bank Structure and Competition, Federal Reserve Bank of Chicago, 419-437.

Berger, A., Davies S., Flannery M., 2000. Comparing market and supervisory assessments of bank performance: Who knows what when? Journal of Money, Credit, and Banking 32, 641-667.

Bessler, W., Nohel, T., 1996. The stock market reaction to dividends cuts and omissions by commercial banks. Journal of Banking and Finance 20, 1485-1508.

Bessler, W., Nohel, T., 2000. Asymmetric information, dividend reductions, and contagion effects in bank stock returns. Journal of Banking and Finance 24, 1831-1848.

Bliss, R., 2001. Market discipline and subordinated debt: A review of some salient issues. Federal Reserve Bank of Chicago Economic Perspectives, 24-45.

Burton, S., Seale, G., 2005. A survey of current and potential uses of market data by the FDIC. FDIC Banking Review 17, 1-17.

Cole, R., Gunther, J., 1995. Separating the likelihood and timing of bank failure. Journal of Banking and Finance 19, 1073-1089.

Covitz, D., Hancock, D., Kwast, M., 2004. A reconsideration of the risk sensitivity of U.S. banking organization subordinated debt spreads: A sample selection approach. Federal Reserve Bank of New York Economic Policy Review 10, 73-92.

Curry, T., Elmer, P., Fissel, G., 2004. Using market information to help identify distressed institutions: A regulatory perspective. FDIC Banking Review 15, 1-16.

DeYoung, R., Flannery, M., Lang, W., Sorescu, S., 2001. The information content of bank exam ratings and subordinated debt prices. Journal of Money, Credit and Banking 33, 900-925.

Evanoff, D., Wall, L., 2000. Subordinated debt and bank capital reform. Working Paper, Federal Reserve Bank of Chicago.

Evanoff, D., Wall, L., 2001. Sub-debt yield spreads as bank risk measures. Journal of Financial Services Research 20, 121-145.

Evanoff, D., Wall, L., 2002. Measures of the riskiness of banking organizations: Subordinated debt yields, risk-based capital, and examination ratings. Journal of Banking and Finance 26, 989-1009.

Financial Services Authority, 2009. The Turner review: A regulatory response to the global banking crisis. London: Financial Services Authority.

Flannery, M., 1998. Using market information in prudential bank supervision: A review of the U.S. empirical evidence. Journal of Money, Credit and Banking 30, 273-305.

Flannery, M., 2005. No pain, no gain? Effecting market discipline via reverse convertible debentures. In: Scott, H.S. (Ed.), Capital adequacy beyond Basel: Banking, securities, and insurance. Oxford, UK: Oxford University Press.

Flannery, M., 2009a. Market-valued triggers will work for contingent capital instruments. Solicited submission to U.S. Treasury Working Group on Bank Capital.

Flannery, M., 2009b. Stabilizing large financial institutions with contingent capital certificates. Working Paper, University of Florida.

Flannery, M., Sorescu, S., 1996. Evidence of bank market discipline in subordinated debentures yields: 1983-1991. Journal of Finance 51, 1347-1377. 
Furlong, F., Williams, R., 2006. Financial market signals and banking supervision: Are current practice consistent with research findings? Federal Reserve Bank of San Francisco Economic Review, 17-29.

Gilbert, A., Meyer, A., Vaughan, M., 1999. The role of supervisory screens and econometric models in off-site surveillance. Federal Reserve Bank of St. Louis Review, 31-56.

Grambsch, P., Therneau, T., 1994. Proportional hazards tests and diagnostics based on weighted residuals. Biometrika 81, 515-526.

Gropp, R., Vesala, J., Vulpes, G., 2006. Equity and bond market signals as leading indicators of bank fragility. Journal of Money, Credit and Banking 38, 399-428.

Hart, O., Zingales, L., 2009. A new capital regulation for large financial institutions. Working Paper, Fondazione Eni Enrico Mattei.

Jagtiani, J., Lemieux, C., 2001. Market discipline prior to bank failure. Journal of Economics and Business 53, 313-324.

Kalbfleisch, J., Prentice, L., 1980. The statistical analysis of failure time data. New York: John Wiley \& Sons.

Krainer, J., Lopez, J., 2008. Using securities market information for bank supervisory monitoring. International Journal of Central Banking 4, 125-164.

Lin, D., Wei, L., 1989. The robust inference for the Cox Proportional Hazard model. Journal of the American Statistical Association 84, 1074-1078.

Peto, R., Peto, J., 1972. Asymptotically efficient rank invariant procedures. Journal of the Royal Statistical Society, Series A135, 185-207.

Prentice, R., 1978. Linear rank tests with right censored data. Biometrika 65, 167-179.

Reidhill, J., O'Keefe, J., 1997. Off-site surveillance systems. In: History of the eighties: Lessons for the future. Washington, DC: Federal Deposit Insurance Corporation, 477-520.

Schmidt, J., 2004. A review of the use of market data in the Federal Reserve System. Conference Paper, Federal Reserve Bank of Cleveland.

Slovin,M., Sushka, M., Polonchek, J., 1999. An analysis of contagion and competitive effects at commercial banks. Journal of Financial Economics, 54, 197-225.

Squam Lake Working Group on Financial Regulation, 2009. An expedited resolution mechanism for distressed financial firms: Regulatory hybrid securities. Policy Paper, Squam Lake Working Group.

Swidler, S., Wilcox, J., 2002. Information about bank risk in options prices. Journal of Banking and Finance 26, 1033-1057.

Wall, L., 2010. Prudential discipline for financial firms: Micro, macro, and market structures. Working Paper, Federal Reserve Bank of Atlanta. 
Figure 1: Nonparametric estimate of the cumulative hazard function, overall sample

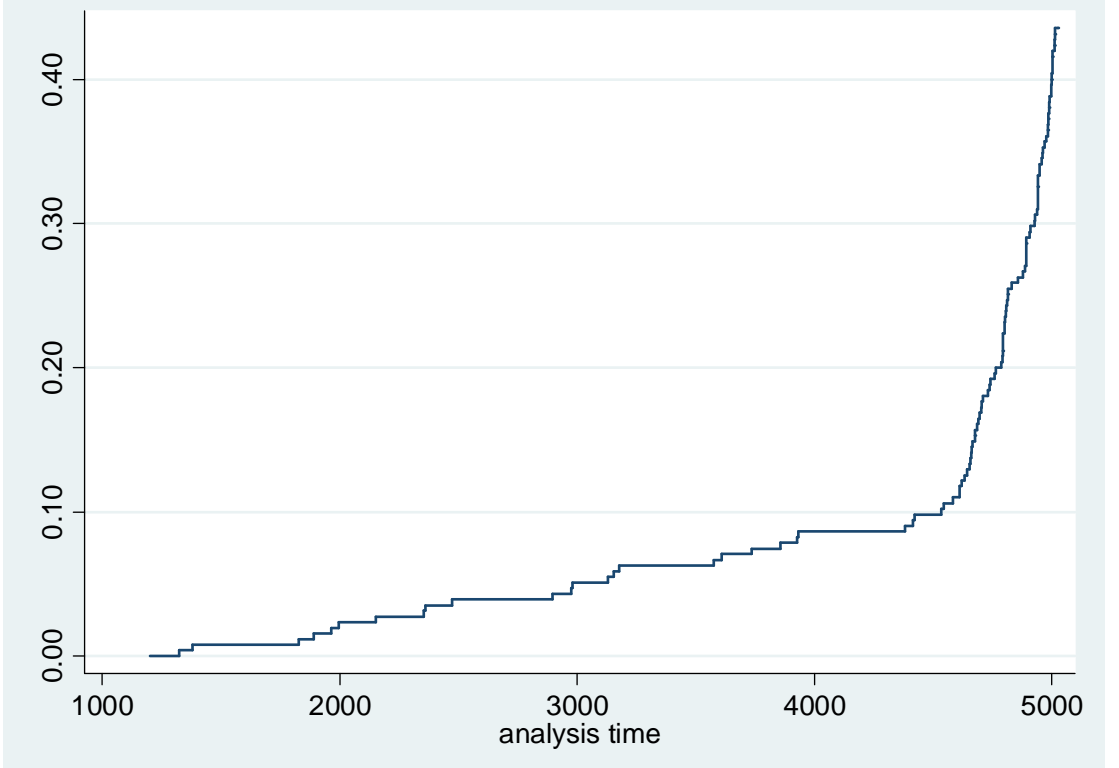


Figure 2: Kaplan-Meier survival estimates, overall sample

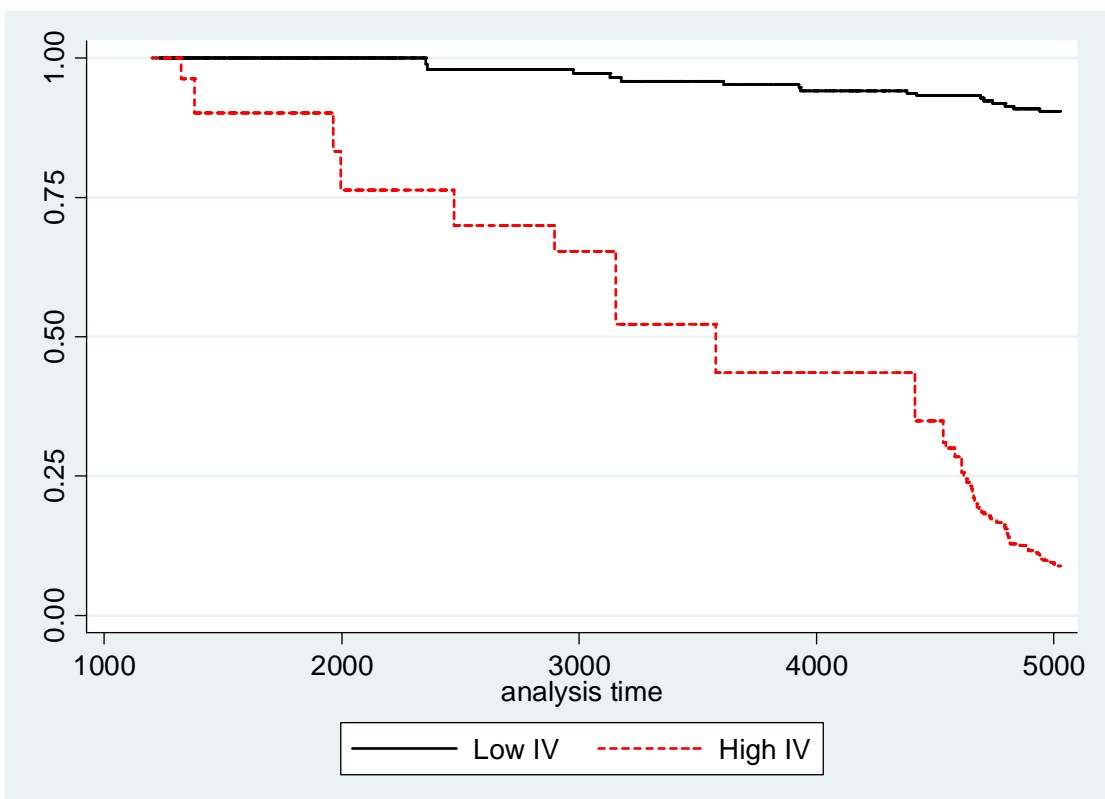

a. By IV level

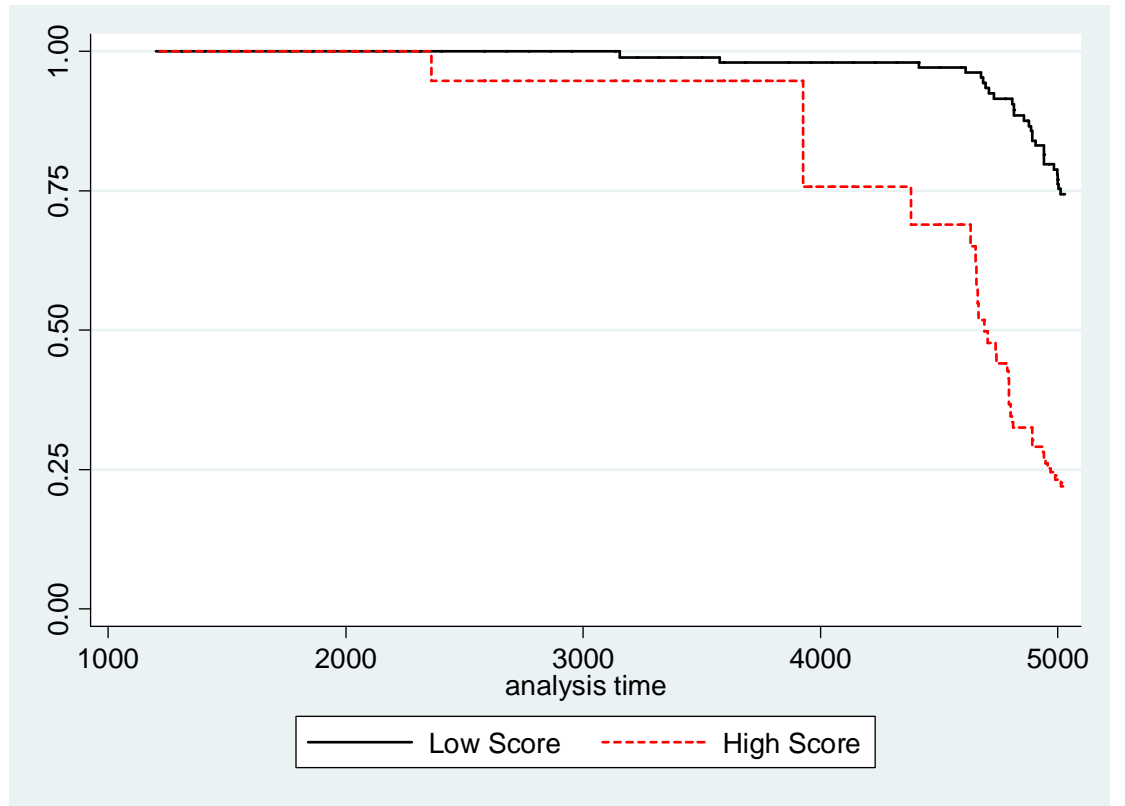

b. By composite rating level 
Figure 3: Covariate-adjusted survivor functions based on Cox PH models (2006-2008)
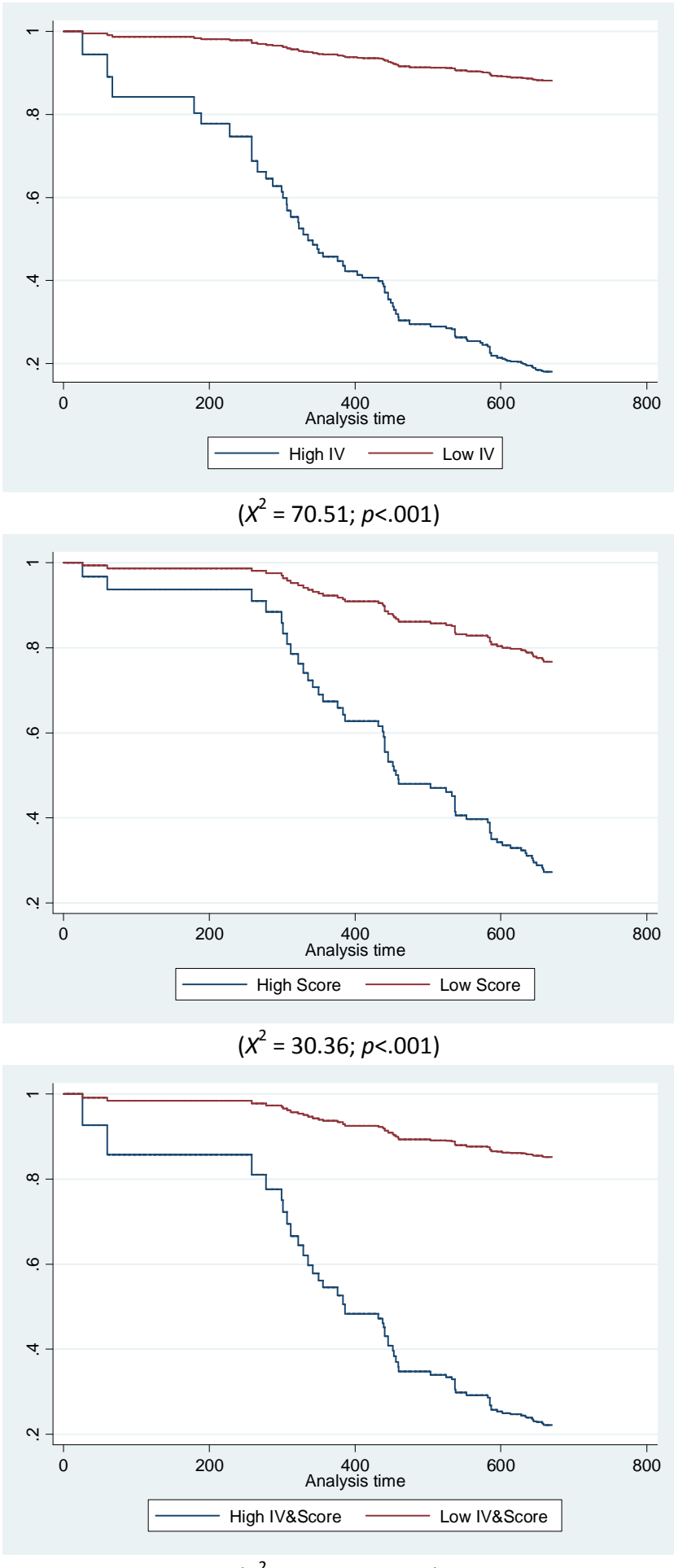

$\left(X^{2}=84.70 ; p<.001\right)$ 
Table 1: Implied Volatility (IV) indicator (\%), by year

\begin{tabular}{ccccccccc}
\hline Year & $\mathbf{N}$ & Mean & St. dev. & Min & Q1 & Median & Q2 & Max \\
\hline \hline 1995 & 9070 & 26.77 & 10.22 & 7.76 & 20.33 & 24.67 & 30.42 & 128.42 \\
1996 & 12061 & 29.08 & 9.66 & 11.40 & 22.81 & 26.64 & 33.01 & 108.87 \\
1997 & 15210 & 33.06 & 11.25 & 6.90 & 25.67 & 30.69 & 37.27 & 115.05 \\
1998 & 22885 & 39.44 & 18.16 & 13.74 & 29.17 & 34.74 & 43.04 & 239.74 \\
1999 & 28476 & 42.74 & 19.84 & 5.30 & 30.22 & 37.15 & 47.88 & 199.96 \\
2000 & 25284 & 48.85 & 21.74 & 7.18 & 35.01 & 42.90 & 55.90 & 225.36 \\
2001 & 26955 & 42.37 & 18.77 & 9.59 & 30.10 & 37.53 & 49.26 & 279.88 \\
2002 & 31850 & 42.54 & 18.44 & 14.08 & 31.02 & 37.76 & 48.03 & 225.90 \\
2003 & 35488 & 35.91 & 16.34 & 13.31 & 26.10 & 32.02 & 39.78 & 187.27 \\
2004 & 39593 & 31.64 & 12.79 & 10.02 & 23.42 & 28.91 & 35.97 & 213.09 \\
2005 & 42361 & 24.23 & 9.67 & 8.48 & 18.08 & 21.47 & 27.71 & 334.05 \\
2006 & 46963 & 24.95 & 9.52 & 6.52 & 18.57 & 22.30 & 28.73 & 102.31 \\
2007 & 57324 & 35.18 & 22.13 & 7.28 & 22.52 & 30.22 & 40.74 & 450.12 \\
2008 & 55668 & 67.23 & 43.53 & 13.71 & 39.80 & 52.97 & $\mathbf{7 9 . 9 0}$ & 490.90 \\
\hline Total & $\mathbf{4 4 9 1 8 8}$ & $\mathbf{3 8 . 8 1}$ & $\mathbf{2 5 . 2 1}$ & $\mathbf{5 . 3 0}$ & $\mathbf{2 4 . 2 2}$ & $\mathbf{3 2 . 5 5}$ & $\mathbf{4 4 . 1 0}$ & $\mathbf{4 9 0 . 9 0}$ \\
\hline \hline
\end{tabular}

Notes: This table presents the time evolution of the IV variable. The "standardized" measure of IV is based on the nearest two "at-the-money" options series -- one above and one below the underlying price -- using values from the nearest expiry month options. We next interpolate between the two IVs to calculate an estimate of the IV for a hypothetically "at-the-money" Call/Put option. Finally, we average the IVs of the two (Call and Put) option contracts to obtain the IV for options with the strike price nearest to the underlying bank stock price. The IVs are computed using the Cox-Ross-Rubinstein binomial tree model to take into account the possibility of early exercise.

Source: authors' computations based on data extracted from Bloomberg 
Table 2: Dividend cuts and suspensions, by sub-sector and year

\begin{tabular}{cccc}
\hline Year & Overall sample & Banks & Financial services firms \\
\hline \hline 1995 & 0 & 0 & 0 \\
1996 & 0 & 0 & 0 \\
1997 & 0 & 0 & 0 \\
1998 & 2 & 1 & 1 \\
1999 & 0 & 0 & 0 \\
2000 & 4 & 0 & 4 \\
2001 & 4 & 1 & 3 \\
2002 & 0 & 0 & 0 \\
2003 & 6 & 0 & 6 \\
2004 & 1 & 0 & 1 \\
2005 & 5 & 1 & 4 \\
2006 & 0 & 0 & 0 \\
2007 & 19 & 5 & 14 \\
2008 & 70 & 35 & 35 \\
\hline Total & $\mathbf{1 1 1}$ & $\mathbf{4 3}$ & $\mathbf{6 8}$ \\
\hline \hline
\end{tabular}

Notes: This table describes the distribution of the event variable by year and by subsector ("banks" vs. "financial services firms"). The financial distress variable was constructed using a twostep procedure. First, we collect from Bloomberg detailed information regarding dividend payouts by all the financial firms included in our final sample over the 1995-2008 period. Second, we use Dow Jones Factiva to identify among all dividend payouts the announcements of dividend cuts and omissions that were released to the financial media: Dow Jones and Reuters newswires; key newspapers such as The Wall Street Journal, The New York Times, Washington Post etc.; and other sources available in Factiva.

Source: authors' computations based on data extracted from Bloomberg and Dow Jones Factiva. 
Table 3: Descriptive statistics on the main variables

\begin{tabular}{|c|c|c|c|c|c|c|c|c|}
\hline \multicolumn{9}{|c|}{ Panel A: Overall sample } \\
\hline Variable name & $\mathbf{N}$ & Mean & Std. Dev. & Min & Q1 & Median & Q3 & Max \\
\hline Total Assets & 621617 & 47021.81 & $1.7 e+05$ & 0.57 & 1304.44 & 4096.80 & 12401.55 & $2.4 e+06$ \\
\hline Implied Volatility & 449188 & 38.81 & 25.21 & 5.30 & 24.22 & 32.55 & 44.10 & 490.90 \\
\hline Composite Score & 287290 & 6.43 & 2.61 & 0.00 & 5.00 & 7.00 & 8.00 & 12.00 \\
\hline Return on Assets & 592427 & 4.02 & 7.18 & -62.10 & 1.12 & 1.76 & 4.93 & 87.03 \\
\hline Non-performing Assets / Tot Assets & 418415 & 0.51 & 1.12 & 0.00 & 0.11 & 0.30 & 0.52 & 26.95 \\
\hline Tot Debt / Common Equity & 621124 & 366.44 & 1020.86 & 0.00 & 73.59 & 158.29 & 306.54 & 39674.62 \\
\hline Efficiency Ratio & 402053 & 68.35 & 641.98 & -3173.09 & 50.89 & 59.78 & 68.40 & 45150.00 \\
\hline Sh-term Borrow / Tot Liab \& Equity & 620614 & 16.32 & 18.76 & 0.00 & 1.82 & 9.52 & 24.72 & 101.78 \\
\hline \multicolumn{9}{|c|}{ Panel B: "Banks" subsample } \\
\hline Total Assets & 225799 & 71161.96 & $2.2 \mathrm{e}+05$ & 205.26 & 4811.81 & 10018.29 & 31202.15 & $2.4 \mathrm{e}+06$ \\
\hline Implied Volatility & 148690 & 34.69 & 21.88 & 5.30 & 22.46 & 29.94 & 38.97 & 410.36 \\
\hline Composite Score & 177329 & 7.17 & 2.05 & 1.00 & 6.00 & 7.00 & 9.00 & 12.00 \\
\hline Return on Assets & 220497 & 1.25 & 0.56 & -5.80 & 1.01 & 1.28 & 1.55 & 4.98 \\
\hline Non-performing Assets / Tot Assets & 181745 & 0.50 & 0.71 & 0.00 & 0.23 & 0.37 & 0.56 & 15.66 \\
\hline Tot Debt / Common Equity & 225799 & 248.07 & 174.18 & 0.00 & 127.38 & 216.25 & 320.01 & 1146.19 \\
\hline Efficiency Ratio & 228647 & 57.15 & 18.91 & -174.03 & 51.58 & 58.15 & 63.41 & 744.35 \\
\hline Sh-term Borrow / Tot Liab \& Equity & 225799 & 10.59 & 8.34 & 0.00 & 4.50 & 8.99 & 14.72 & 75.47 \\
\hline \multicolumn{9}{|c|}{ Panel A: "Financial services firms" subsample } \\
\hline Total Assets & 395818 & 33250.77 & $1.3 e+05$ & 0.57 & 755.78 & 2169.47 & 5859.33 & $1.2 \mathrm{e}+06$ \\
\hline Implied Volatility & 300498 & 40.85 & 26.47 & 6.52 & 25.22 & 34.15 & 46.97 & 490.90 \\
\hline Composite Score & 109961 & 5.24 & 2.96 & 0.00 & 3.00 & 5.00 & 8.00 & 12.00 \\
\hline Return on Assets & 371930 & 5.66 & 8.64 & -62.10 & 1.53 & 3.81 & 7.33 & 87.03 \\
\hline Non-performing Assets / Tot Assets & 236670 & 0.51 & 1.35 & 0.00 & 0.00 & 0.22 & 0.47 & 26.95 \\
\hline Tot Debt / Common Equity & 395325 & 434.05 & 1267.87 & 0.00 & 52.34 & 121.94 & 281.45 & 39674.62 \\
\hline Efficiency Ratio & 173406 & 83.12 & 977.09 & -3173.09 & 48.11 & 65.69 & 78.38 & 45150.00 \\
\hline Sh-term Borrow / Tot Liab \& Equity & 394815 & 19.60 & 22.00 & 0.00 & 0.28 & 11.15 & 34.42 & 101.78 \\
\hline
\end{tabular}

Notes: This table presents descriptive statistics on key financial variables measuring four main dimensions of the financial firms' performance (risk, profitability, efficiency, and capitalization), option market indicator, composite score and other control variables calculated separately for the full sample and two sub-samples of firms: "banks" and "financial services firms." See text for definition of variables.

Source: authors' computations based on data extracted from Bloomberg 
Table 4: Stratified tests for equality of survivor functions

\begin{tabular}{|c|c|c|c|}
\hline \multirow[b]{2}{*}{ Subgroups based on IV } & \multicolumn{3}{|c|}{ Panel A: Overall sample } \\
\hline & Events observed & Events expected* & Sum of ranks ${ }^{\top}$ \\
\hline Low IV value & 16 & 66.44 & -39.881 \\
\hline High IV value & 88 & 37.56 & 39.881 \\
\hline Total & 104 & 104.00 & 0 \\
\hline \multirow[t]{2}{*}{ Chi Square Statistic } & & $193.72 * * *$ & \\
\hline & \multicolumn{3}{|c|}{ Panel B: "Banks" subsample } \\
\hline Subgroups based on IV & Events observed & Events expected & Sum of ranks \\
\hline Low IV value & 8 & 26.03 & -13.470 \\
\hline High IV value & 34 & 15.97 & 13.470 \\
\hline Total & 42 & 42.00 & 0 \\
\hline \multirow[t]{2}{*}{ Chi Square Statistic } & & $54.51 * * *$ & \\
\hline & \multicolumn{3}{|c|}{ Panel C: "Financial services firms" subsample } \\
\hline Subgroups based on IV & Events observed & Events expected & Sum of ranks \\
\hline Low IV value & 8 & 40.42 & -25.954 \\
\hline High IV value & 54 & 21.58 & 25.954 \\
\hline Total & 62 & 62.00 & 0 \\
\hline \multicolumn{2}{|l|}{ Chi Square Statistic } & $146.11 * * *$ & \\
\hline
\end{tabular}

Notes: This table presents overall and within-stratum tests based on Peto and Peto (1972) and Prentice (1978). The test statistics use as the weight function an estimate of the Kaplan-Meier survivor function. Compared with other tests for equality of survivor functions, this test is designed for the special cases when the hazard functions are supposed to vary in ways other than proportionally. The test is not affected by differences in censoring patterns across subgroups/stratum.

$* * *$ statistical significance at the $1 \%$ level

${ }^{\mathrm{T}}$ sum over calculations within strata 
Table 5: Results from Cox Proportional Hazards regressions: IV indicator

\begin{tabular}{|c|c|c|c|c|c|c|c|c|c|c|}
\hline \multirow{2}{*}{$\begin{array}{l}\text { Independent } \\
\text { Variable } \\
\text { IV continuous }\end{array}$} & \multicolumn{4}{|c|}{ Overall sample } & \multicolumn{2}{|c|}{ "Banks" subsample } & \multicolumn{2}{|c|}{$\begin{array}{l}\text { "Financial services } \\
\text { firms" subsample }\end{array}$} & \multicolumn{2}{|c|}{$\begin{array}{c}\text { Stratified } \\
\text { estimations }\end{array}$} \\
\hline & $\begin{array}{c}0.016 * * * \\
(0.000)\end{array}$ & & $\begin{array}{c}0.017 * * * \\
(0.000)\end{array}$ & & $\begin{array}{c}0.016 * * * \\
(0.000)\end{array}$ & & $\begin{array}{c}0.018 * * * \\
(0.000)\end{array}$ & & $\begin{array}{c}0.017^{* * *} \\
(0.000)\end{array}$ & \\
\hline IV dummy & & $\begin{array}{c}3.374 * * * \\
(0.000)\end{array}$ & & $\begin{array}{c}3.430 * * * \\
(0.000)\end{array}$ & & $\begin{array}{c}2.807^{* * *} \\
(0.000)\end{array}$ & & $\begin{array}{c}3.695 * * * \\
(0.000)\end{array}$ & & $\begin{array}{c}3.377^{* * *} \\
(0.000)\end{array}$ \\
\hline Bank dummy & & & $\begin{array}{c}0.662 * * * \\
(0.001)\end{array}$ & $\begin{array}{l}0.540 * * * \\
(0.008)\end{array}$ & & & & & & \\
\hline No. of firms & 255 & 255 & 255 & 255 & 75 & 75 & 180 & 180 & 255 & 255 \\
\hline No. of div. cuts & 104 & 104 & 104 & 104 & 42 & 42 & 62 & 62 & 104 & 104 \\
\hline Log likelihood & -501.2 & -477.0 & -496.2 & -473.6 & -163.4 & -152.3 & -262.5 & -252.6 & -426.1 & -405.8 \\
\hline Wald test & $167.0 * * *$ & $113.8^{* * *}$ & $167.9^{* * *}$ & $116.8^{* * *}$ & $30.2^{* * *}$ & $31.7^{* * *}$ & $122.3^{* * *}$ & $75.4^{* * *}$ & $152.6 * * *$ & $104.6^{* * *}$ \\
\hline Prop.-haz. test & $10.74 * * *$ & 0.02 & $11.51^{* * *}$ & 0.27 & $8.37^{* * *}$ & 0.12 & $5.56 * *$ & 0.92 & $12.5^{\top} * * *$ & $0.01^{\top}$ \\
\hline
\end{tabular}

Notes: This table presents the estimation results from Cox Proportional Hazards (PH) regressions using various sets of basic time-varying covariates based on IV level. The dependent variable is the time-to-failure, i.e. the duration (measured in days) until the announcement of a dividend cut / suspension or censoring. Standard errors are corrected for clustering. Coefficients, not hazard ratios, are reported; $p$-values are reported in parenthesis, below each coefficient estimate.

$* * *, * *, *$ indicate statistical significance at the $1 \%, 5 \%$, and $10 \%$ respectively

${ }^{\top}$ The Grambsch and Therneau (1994) tests of the proportional-hazards assumption assume homogeneity of variance across subgroups. This assumption may not hold in the special case of the stratified Cox regression. That's why the proportional-hazards assumption was checked in this case separately for each stratum. 
Table 6: Results from Cox Proportional Hazards regressions: IV indicator and composite score based on time-varying financial ratios

\begin{tabular}{|c|c|c|c|c|c|c|c|c|c|c|c|c|}
\hline \multirow{2}{*}{$\begin{array}{l}\text { Independent Variable } \\
\text { Composite score }\end{array}$} & \multicolumn{5}{|c|}{ Overall sample } & \multicolumn{2}{|c|}{ "Banks" subsample } & \multicolumn{2}{|c|}{$\begin{array}{l}\text { "Financial services } \\
\text { firms" subsample }\end{array}$} & \multicolumn{3}{|c|}{ Stratified estimations $^{\top}$} \\
\hline & $\begin{array}{c}0.337^{* * *} \\
(0.000)\end{array}$ & $\begin{array}{c}0.246^{* * *} \\
(0.000)\end{array}$ & $\begin{array}{c}0.201^{* * *} \\
(0.005)\end{array}$ & $\begin{array}{c}0.352^{* * *} \\
(0.000)\end{array}$ & $\begin{array}{l}0.185^{* *} \\
(0.010)\end{array}$ & $\begin{array}{c}0.620^{* * *} \\
(0.000)\end{array}$ & $\begin{array}{c}0.487^{* * *} \\
(0.000)\end{array}$ & $\begin{array}{c}0.187^{* * *} \\
(0.000)\end{array}$ & $\begin{array}{l}0.095^{* *} \\
(0.036)\end{array}$ & $\begin{array}{c}0.348^{* * *} \\
(0.000)\end{array}$ & $\begin{array}{c}0.228^{* * *} \\
(0.001)\end{array}$ & $\begin{array}{l}0.177^{* *} \\
(0.015)\end{array}$ \\
\hline IV continuous & & $\begin{array}{c}0.017^{* * *} \\
(0.000)\end{array}$ & & & & & $\begin{array}{c}0.012^{* * *} \\
(0.000)\end{array}$ & & $\begin{array}{c}0.025^{* * *} \\
(0.000)\end{array}$ & & $\begin{array}{c}0.018 * * * \\
(0.000)\end{array}$ & \\
\hline IV dummy & & & $\begin{array}{c}3.216 * * * \\
(0.000)\end{array}$ & & $\begin{array}{c}3.290 * * * \\
(0.000)\end{array}$ & & & & & & & $\begin{array}{r}3.440^{* * *} \\
(0.000)\end{array}$ \\
\hline Bank dummy & & & & $\begin{array}{l}-0.343 \\
(0.201) \\
\end{array}$ & $\begin{array}{c}0.232 \\
(0.334) \\
\end{array}$ & & & & & & & \\
\hline No of firms & 126 & 126 & 126 & 126 & 126 & 71 & 71 & 55 & 55 & 126 & 126 & 126 \\
\hline No of dividend cuts & 62 & 61 & 61 & 62 & 61 & 40 & 39 & 22 & 22 & 62 & 61 & 61 \\
\hline Log (pseudo-)likelihood & -278.5 & -246.5 & -234.1 & -277.7 & -233.8 & -148.1 & -133.9 & -83.6 & -67.5 & -237.9 & -206.9 & -193.4 \\
\hline Wald test & $17.2^{* * *}$ & $103.9 * * *$ & $59.2^{* * *}$ & $21.75^{* * *}$ & $59.42 * * *$ & $34.72^{* * *}$ & $79.15^{* * *}$ & $5.30 * *$ & $34.63 * * *$ & $19.14^{* * *}$ & $102.41 * * *$ & $44.34 * * *$ \\
\hline Proportional-hazards test & $11.29 * * *$ & $11.62 * * *$ & 3.23 & $10.25 * * *$ & 3.86 & $7.86 * * *$ & $7.97 * *$ & 0.28 & $10.53^{* * *}$ & $8.64^{\top} * * *$ & $11.06^{\top} * * *$ & $2.44^{\top}$ \\
\hline
\end{tabular}

Notes: This table presents the estimation results from Cox Proportional Hazards (PH) regressions using various sets of basic time-varying covariates based on IV and composite rating levels. The dependent variable is the time-to-failure, i.e. the duration (measured in days) until the announcement of a dividend cut / suspension or censoring. Standard errors are corrected for clustering. Coefficients, not hazard ratios, are reported; $p$-values are reported in parenthesis, below each coefficient estimate.

$* * *, * *, *$ indicate statistical significance at the $1 \%, 5 \%$, and $10 \%$ respectively

The Grambsch and Therneau (1994) tests of the proportional-hazards assumption assume homogeneity of variance across subgroups. This assumption may not hold in the special case of the stratified Cox regression. That's why the proportional-hazards assumption was checked in this case separately for each stratum. 
Table 7: Results from "parametric" (log-logistic) survival-time models: IV indicator, composite score and firm-specific time-varying financial ratios

\begin{tabular}{|c|c|c|c|c|c|c|c|c|c|c|c|}
\hline Independent Variable & Model 1 & Model 2 & Model 3 & Model 4 & Model 5 & Model 6 & Model 7 & Model 8 & Model 9 & Model 10 & Model 11 \\
\hline IV continuous & $\begin{array}{c}-0.014^{* * *} \\
(0.000)\end{array}$ & & & & & $\begin{array}{c}-0.007^{* * *} \\
(0.001)\end{array}$ & & $\begin{array}{c}-0.008^{* * *} \\
(0.000)\end{array}$ & & $\begin{array}{c}-0.009^{* * *} \\
(0.000)\end{array}$ & \\
\hline IV dummy & & $\begin{array}{c}-0.780^{* * *} \\
(0.000\end{array}$ & & & & & $\begin{array}{c}-0.463^{* * *} \\
(0.000)\end{array}$ & & $\begin{array}{c}-0.472^{* * *} \\
(0.000)\end{array}$ & & $\begin{array}{c}-0.698^{* * *} \\
(0.000)\end{array}$ \\
\hline Composite score & & & $\begin{array}{c}-0.034^{* *} \\
(0.014)\end{array}$ & & & $\begin{array}{c}-0.046 * \\
(0.056)\end{array}$ & $\begin{array}{c}-0.046 * * * \\
(0.006)\end{array}$ & & & & \\
\hline Return on Assets & & & & $\begin{array}{c}0.005 \\
(0.431)\end{array}$ & $\begin{array}{c}0.006 \\
(0.426)\end{array}$ & & & $\begin{array}{l}0.006^{*} \\
(0.060)\end{array}$ & $\begin{array}{c}0.007^{* * *} \\
(0.004)\end{array}$ & $\begin{array}{c}0.003 \\
(0.480)\end{array}$ & $\begin{array}{l}0.005^{*} \\
(0.095)\end{array}$ \\
\hline Non-perf Assets / Tot Assets & & & & $\begin{array}{c}-0.043^{* * *} \\
(0.000)\end{array}$ & $\begin{array}{c}-0.042^{* * *} \\
(0.000)\end{array}$ & & & $\begin{array}{c}-0.020^{*} \\
(0.084)\end{array}$ & $\begin{array}{c}-0.024^{* * *} \\
(0.003)\end{array}$ & $\begin{array}{l}-0.023 \\
(0.222)\end{array}$ & $\begin{array}{c}-0.029 * * * \\
(0.000)\end{array}$ \\
\hline Tot Debt / Common Equity & & & & $\begin{array}{c}-0.000^{* *} \\
(0.013)\end{array}$ & $\begin{array}{c}-0.000^{* *} \\
(0.048)\end{array}$ & & & $\begin{array}{l}-0.000 \\
(0.350)\end{array}$ & $\begin{array}{c}-0.000^{*} \\
(0.063)\end{array}$ & $\begin{array}{l}-0.000 \\
(0.235)\end{array}$ & $\begin{array}{c}-0.000^{* *} \\
(0.016)\end{array}$ \\
\hline Efficiency Ratio & & & & $\begin{array}{l}-0.000 \\
(0.268)\end{array}$ & $\begin{array}{l}-0.000 \\
(0.263)\end{array}$ & & & $\begin{array}{c}-0.000^{*} \\
(0.081)\end{array}$ & $\begin{array}{c}-0.000 * * \\
(0.049)\end{array}$ & $\begin{array}{c}-0.000 * * \\
(0.027)\end{array}$ & $\begin{array}{c}-0.000^{*} \\
(0.092)\end{array}$ \\
\hline ST Borrow / Tot Liab \& Equity & & & & & $\begin{array}{c}0.001 \\
(0.494)\end{array}$ & & & $\begin{array}{c}0.003 \\
(0.205)\end{array}$ & $\begin{array}{c}0.005^{* *} \\
(0.010)\end{array}$ & $\begin{array}{c}0.002 \\
(0.486)\end{array}$ & $\begin{array}{c}0.005^{* *} \\
(0.019)\end{array}$ \\
\hline Bank dummy & & & & & & & & & & $\begin{array}{c}-0.148^{* *} \\
(0.049)\end{array}$ & $\begin{array}{c}-0.291^{* * *} \\
(0.006)\end{array}$ \\
\hline Constant & $\begin{array}{c}9.377^{* * *} \\
(0.000) \\
\end{array}$ & $\begin{array}{c}8.834^{* * *} \\
(0.000)\end{array}$ & $\begin{array}{c}8.819 * * * \\
(0.000)\end{array}$ & $\begin{array}{c}8.624^{* * *} \\
(0.000)\end{array}$ & $\begin{array}{c}8.618^{* * *} \\
(0.000) \\
\end{array}$ & $\begin{array}{c}9.361^{* * *} \\
(0.000) \\
\end{array}$ & $\begin{array}{c}9.068^{* * *} \\
(0.000) \\
\end{array}$ & $\begin{array}{c}9.035^{* * *} \\
(0.000) \\
\end{array}$ & $\begin{array}{c}8.692^{* * *} \\
(0.000)\end{array}$ & $\begin{array}{c}9.209^{* * *} \\
(0.000)\end{array}$ & $\begin{array}{c}8.973 * * * \\
(0.000)\end{array}$ \\
\hline No of firms & 255 & 255 & 126 & 126 & 126 & 126 & 126 & 126 & 126 & 126 & 126 \\
\hline No of dividend cuts & 104 & 104 & 62 & 62 & 62 & 61 & 61 & 61 & 61 & 61 & 61 \\
\hline Ancillary/Gamma & 0.147 & 0.135 & 0.066 & 0.065 & 0.065 & 0.081 & 0.079 & 0.082 & 0.079 & 0.085 & 0.078 \\
\hline Log (pseudo-)likelihood & 32.41 & 32.15 & 23.70 & 22.48 & 22.86 & 67.20 & 67.18 & 62.05 & 63.42 & 64.10 & 66.91 \\
\hline Wald test (all covariates) & $27.76 * * *$ & $50.01 * * *$ & $6.01 * *$ & $38.43 * * *$ & $29.42 * * *$ & $32.93 * * *$ & $55.27 * * *$ & $46.79 * * *$ & $142.98 * * *$ & $46.65^{* * *}$ & $192.35^{* * *}$ \\
\hline Wald test (financial ratios) & . & . & $6.01 * *$ & $38.43 * * *$ & $29.42 * * *$ & $3.65 *$ & $7.46 * * *$ & $9.60 *$ & $28.49 * * *$ & $11.69 * *$ & $35.82 * * *$ \\
\hline Wald test (implied volatility) & $27.76 * * *$ & $50.01 * * *$ & . & . & . & $11.35^{* * *}$ & $27.30 * * *$ & $15.29 * * *$ & $46.39 * * *$ & $12.54^{* * *}$ & $47.75^{* * *}$ \\
\hline AIC & -58.81 & -58.30 & -41.40 & -32.97 & -31.72 & -126.41 & -126.37 & -108.09 & -110.84 & -110.2039 & -115.8251 \\
\hline
\end{tabular}

Notes: This table presents the estimation results from the log-logistic regressions using various sets of time-varying covariates. The dependent variable is the natural logarithm of the survival time, i.e. the duration (measured in days) until the announcement of a dividend cut / suspension or censoring. Standard errors are corrected for clustering. For computational reasons, it is worth

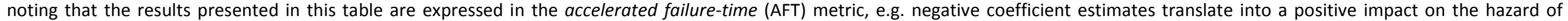
"failure", whereas a positive coefficient estimate implies that a change in the covariate decreases the hazard. $P$-values are reported in parentheses, below each coefficient estimate.

$* * *, * *, *$ indicate statistical significance at the $1 \%, 5 \%$, and $10 \%$ respectively 
Table 8a: Explaining survival probabilities in a high-stress financial world (2006--2008) I. Cox Proportional Hazards regressions

\begin{tabular}{|c|c|c|c|c|c|c|}
\hline \multirow{2}{*}{$\begin{array}{l}\text { Independent Variable } \\
\text { IV dummy }\end{array}$} & \multicolumn{4}{|c|}{ Overall sample } & \multicolumn{2}{|c|}{ Stratified estimations $^{\top}$} \\
\hline & $\begin{array}{c}2.609 * * * \\
(0.000)\end{array}$ & $\begin{array}{c}2.582 * * * \\
(0.000)\end{array}$ & $\begin{array}{c}1.686 * * * \\
(0.000)\end{array}$ & $\begin{array}{c}1.681^{* * *} \\
(0.000)\end{array}$ & $\begin{array}{c}2.565 * * * \\
(0.000)\end{array}$ & $\begin{array}{c}1.688^{* * *} \\
(0.000)\end{array}$ \\
\hline Composite score & & & $\begin{array}{c}0.257 * * * \\
(0.003)\end{array}$ & $\begin{array}{c}0.259 * * * \\
(0.003)\end{array}$ & & $\begin{array}{c}0.255^{* * *} \\
(0.003)\end{array}$ \\
\hline Bank dummy & & $\begin{array}{c}0.581 * * * \\
(0.002)\end{array}$ & & $\begin{array}{l}-0.025 \\
(0.925) \\
\end{array}$ & & \\
\hline No of firms & 255 & 255 & 126 & 126 & 255 & 126 \\
\hline No of div cuts & 88 & 88 & 57 & 57 & 88 & 57 \\
\hline Log (pseudo-)likelihood & -429.25 & -425.8 & -236.0 & -236.0 & -366.7 & -199.7 \\
\hline Wald test & $70.51^{* * *}$ & $98.59 * * *$ & $81.79 * * *$ & $81.77^{* * *}$ & $66.17 * * *$ & $83.48 * * *$ \\
\hline Proportional-hazards test & 2.52 & 2.93 & 3.98 & $6.54^{*}$ & $2.75^{*}$ & $4.67^{*}$ \\
\hline
\end{tabular}

Notes: This table presents the estimation results over the period 2006--2008 from Cox Proportional Hazards (PH) regressions using various sets of basic time-varying covariates based on IV and composite rating levels. The dependent variable is the time-to-failure, i.e. the duration (measured in days) until the announcement of a dividend cut / suspension or censoring. We only report $\mathrm{CPH}$ models for which the proportional hazards assumption holds, i.e. the PH test statistic is not significant at the $5 \%$ level. Standard errors are corrected for clustering. Coefficients, not hazard ratios, are reported; $p$-values are reported in parenthesis, below each coefficient estimate.

$* * *, * *, *$ indicate statistical significance at the $1 \%, 5 \%$, and $10 \%$ respectively

T The Grambsch and Therneau (1994) tests of the proportional-hazards assumption assume homogeneity of variance across subgroups. This assumption may not hold in the special case of the stratified Cox regression. That's why the proportionalhazards assumption was checked in this case separately for each stratum. 
Table 8b: Explaining survival probabilities in a high-stress financial world (2006--2008): Il. Accelerated Failure-Time models

\begin{tabular}{|c|c|c|c|c|c|c|c|c|c|c|c|}
\hline Independent Variable & Model 1 & Model 2 & Model 3 & Model 4 & Model 5 & Model 6 & Model 7 & Model 8 & Model 9 & Model 10 & Model 11 \\
\hline IV continuous & $\begin{array}{c}-0.009 * * * \\
(0.002)\end{array}$ & & & & & $\begin{array}{c}-0.005^{* * *} \\
(0.000)\end{array}$ & & $\begin{array}{c}-0.006 * \\
(0.056)\end{array}$ & & $\begin{array}{c}-0.007 * * * \\
(0.005)\end{array}$ & \\
\hline IV dummy & & $\begin{array}{c}-0.413^{* * *} \\
(0.000)\end{array}$ & & & & & $\begin{array}{c}-0.285^{* * *} \\
(0.000)\end{array}$ & & $\begin{array}{c}-0.342^{* *} \\
(0.029)\end{array}$ & & $\begin{array}{c}-0.303^{* *} \\
(0.015)\end{array}$ \\
\hline Composite score & & & $\begin{array}{c}-0.020^{* * *} \\
(0.002)\end{array}$ & & & $\begin{array}{c}-0.040 * * * \\
(0.008)\end{array}$ & $\begin{array}{c}-0.032^{* *} \\
(0.015)\end{array}$ & & & & \\
\hline Return on Assets & & & & $\begin{array}{c}0.002 \\
(0.557)\end{array}$ & $\begin{array}{c}0.002 \\
(0.560)\end{array}$ & & & $\begin{array}{c}0.003 \\
(0.464)\end{array}$ & $\begin{array}{c}0.001 \\
(0.709)\end{array}$ & $\begin{array}{l}-0.004 \\
(0.225)\end{array}$ & $\begin{array}{c}0.000 \\
(0.984)\end{array}$ \\
\hline Non-perf Ass / Tot Assets & & & & $\begin{array}{l}-0.056 \\
(0.282)\end{array}$ & $\begin{array}{l}-0.055 \\
(0.324)\end{array}$ & & & $\begin{array}{c}-0.049 * \\
(0.073)\end{array}$ & $\begin{array}{c}-0.067^{* *} \\
(0.020)\end{array}$ & $\begin{array}{c}-0.079 * * * \\
(0.010)\end{array}$ & $\begin{array}{c}-0.058^{* *} \\
(0.015)\end{array}$ \\
\hline Tot Debt / Common Equity & & & & $\begin{array}{l}-0.000 \\
(0.114)\end{array}$ & $\begin{array}{l}-0.000 \\
(0.123)\end{array}$ & & & $\begin{array}{l}-0.000 \\
(0.258)\end{array}$ & $\begin{array}{c}-0.000^{* * *} \\
(0.003)\end{array}$ & $\begin{array}{c}-0.000 * * * \\
(0.006)\end{array}$ & $\begin{array}{c}-0.000 * * * \\
(0.001)\end{array}$ \\
\hline Efficiency Ratio & & & & $\begin{array}{l}-0.000 \\
(0.573)\end{array}$ & $\begin{array}{l}-0.000 \\
(0.576)\end{array}$ & & & $\begin{array}{c}-0.000 * * \\
(0.015)\end{array}$ & $\begin{array}{l}-0.000 \\
(0.194)\end{array}$ & $\begin{array}{c}-0.000^{* *} \\
(0.021)\end{array}$ & $\begin{array}{l}-0.000 \\
(0.261)\end{array}$ \\
\hline ST Borrow / Tot Liab \& Eq & & & & & $\begin{array}{c}0.000 \\
(0.988)\end{array}$ & & & $\begin{array}{c}0.001 \\
(0.503)\end{array}$ & $\begin{array}{c}0.001 \\
(0.530)\end{array}$ & $\begin{array}{l}-0.002 \\
(0.397)\end{array}$ & $\begin{array}{c}0.000 \\
(0.824)\end{array}$ \\
\hline Bank dummy & & & & & & & & & & $\begin{array}{c}-0.239 * * * \\
(0.004)\end{array}$ & $\begin{array}{l}-0.050 \\
(0.344)\end{array}$ \\
\hline Constant & $\begin{array}{c}9.115^{* * *} \\
(0.000)\end{array}$ & $\begin{array}{c}8.860 * * * \\
(0.000)\end{array}$ & $\begin{array}{c}8.704^{* * *} \\
(0.000)\end{array}$ & $\begin{array}{c}8.626 * * * \\
(0.000)\end{array}$ & $\begin{array}{c}8.626^{* * *} \\
(0.000)\end{array}$ & $\begin{array}{c}9.233^{* * *} \\
(0.000)\end{array}$ & $\begin{array}{c}9.004^{* * *} \\
(0.000)\end{array}$ & $\begin{array}{c}9.033^{* * *} \\
(0.000)\end{array}$ & $\begin{array}{c}8.929 * * * \\
(0.000)\end{array}$ & $\begin{array}{c}9.332 * * * \\
(0.000)\end{array}$ & $\begin{array}{c}8.916^{* * *} \\
(0.000)\end{array}$ \\
\hline No of firms & 255 & 255 & 126 & 126 & 126 & 126 & 126 & 126 & 126 & 126 & 126 \\
\hline No of dividend cuts & 88 & 88 & 58 & 58 & 58 & 57 & 57 & 57 & 57 & 57 & 57 \\
\hline Ancillary/Gamma & 0.071 & 0.081 & 0.039 & 0.047 & 0.047 & 0.052 & 0.061 & 0.059 & 0.057 & 0.056 & 0.058 \\
\hline Log (pseudo-)likelihood & 107.12 & 77.78 & 51.14 & 50.63 & 50.63 & 90.18 & 74.69 & 83.02 & 76.21 & 89.20 & 76.78 \\
\hline Wald test (all covariates) & $9.37^{* * *}$ & $12.43 * * *$ & $9.62^{* * *}$ & 2.77 & 2.81 & $28.80 * * *$ & $21.12^{* * *}$ & $14.70^{* *}$ & $13.18^{* *}$ & $25.96 * * *$ & $26.29 * * *$ \\
\hline Wald test (financial ratios) & . & . & $9.62 * * *$ & 2.77 & 2.81 & $7.14^{* * *}$ & $5.95^{* *}$ & $14.70^{* *}$ & $13.09 * *$ & $18.55^{* * *}$ & $16.52^{* * *}$ \\
\hline Wald test (imp volatility) & $9.37^{* * *}$ & $12.43 * * *$ & . & . & . & $12.89 * * *$ & $14.13^{* * *}$ & $3.66^{*}$ & $4.80 * *$ & $7.75^{* * *}$ & $5.92 * *$ \\
\hline AIC & -208.25 & -149.55 & -96.27 & -89.25 & -87.25 & -172.36 & -141.37 & -150.04 & -136.43 & -160.40 & -135.57 \\
\hline
\end{tabular}

Notes: This table presents the estimation results over the period 2006--2008 from the log-logistic regressions using various sets of time-varying covariates. The dependent variable is the

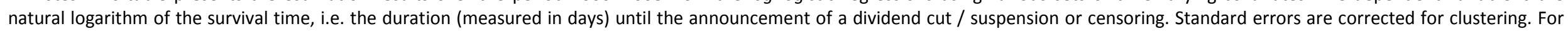
computational reasons, it is worth noting that the results presented in this table are expressed in the accelerated failure-time (AFT) metric, e.g. negative coefficient estimates translate into a positive impact on the hazard of "failure", whereas a positive coefficient estimate implies that a change in the covariate decreases the hazard. $P$-values are reported in parentheses, below each coefficient estimate. $* * *, * *, *$ indicate statistical significance at the $1 \%, 5 \%$, and $10 \%$ respectively 


\section{PREDiCTing FinANCIAL DistRess}

Table 9: The Cox PH model: in-sample classification accuracy

\begin{tabular}{lccccccc}
\hline Time observed & 3 months & 6 months & 9 months & 12 months & 15 months & 18 months & 21 months \\
\hline \multicolumn{1}{l}{ Implied Volatility } & & & & & & & \\
Low IV & $98.7 \%$ & $98.2 \%$ & $96.3 \%$ & $93.8 \%$ & $91.4 \%$ & $90.2 \%$ & $88.2 \%$ \\
High IV & $84.2 \%$ & $77.7 \%$ & $59.9 \%$ & $42.2 \%$ & $29.5 \%$ & $24.5 \%$ & $18.0 \%$ \\
Discriminatory power & $14.5 \%$ & $20.4 \%$ & $36.4 \%$ & $51.6 \%$ & $61.9 \%$ & $65.7 \%$ & $70.1 \%$ \\
\hline & & & & & & & \\
$\quad$ Composite score & & & & & & & \\
Low score & $98.7 \%$ & $98.7 \%$ & $96.4 \%$ & $91.0 \%$ & $86.1 \%$ & $82.9 \%$ & $76.8 \%$ \\
High score & $93.7 \%$ & $93.7 \%$ & $83.3 \%$ & $62.8 \%$ & $48.1 \%$ & $39.7 \%$ & $27.3 \%$ \\
Discriminatory power & $5.0 \%$ & $5.0 \%$ & $13.0 \%$ & $28.2 \%$ & $38.1 \%$ & $43.1 \%$ & $49.5 \%$ \\
\hline & & & & & & & \\
$\quad$ IV \& score & & & & & & & \\
Low IV \& score & $98.4 \%$ & $98.4 \%$ & $96.6 \%$ & $92.5 \%$ & $89.3 \%$ & $87.7 \%$ & $85.2 \%$ \\
High IV \& score & $85.8 \%$ & $85.8 \%$ & $72.2 \%$ & $48.3 \%$ & $34.7 \%$ & $29.2 \%$ & $22.2 \%$ \\
Discriminatory power & $12.6 \%$ & $12.6 \%$ & $24.4 \%$ & $44.3 \%$ & $54.6 \%$ & $58.5 \%$ & $63.0 \%$ \\
\hline
\end{tabular}

Note: This table presents the covariate-adjusted survivor functions based on three distinct Cox PH models estimated over the 2006--2008 period: (1) a model including the IV market-based indicator; (2) a model including the composite score variable; (3) a model including both the IV indicator and composite score. All estimated hazard ratios in the three models are significant at the $5 \%$ level. The log rank tests for the equality of survivor functions indicate significance at the $1 \%$ level. 